\title{
أثرموقع البديل الصحيح في اختبار اختيار من متعدد على دقة تقدير معالم الفقرة وفق النموذج ثنائي المعلمة لنظرية الاستجابة للفقرة
}

\author{
أشواق ضيف الله سليم المرو اني \\ ماجستير في القياس والتقويم - جامعة تبوك- المملكة العربية السعودية المباتية \\ A.ashwaqalmarwani@hotmail.com \\ شاهرخالد سليمان \\ أستاذ مشارك في القياس والتقويم - جامعة تبوك - المملكة العربية السعودية سليمان \\ s.suliman@ut.edu.sa
}

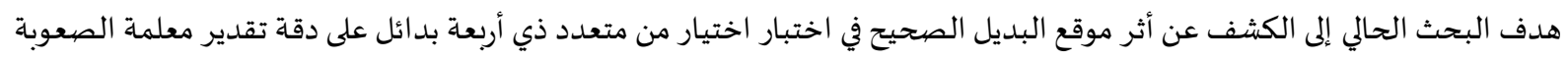

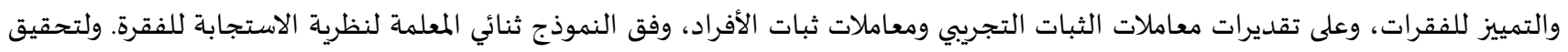

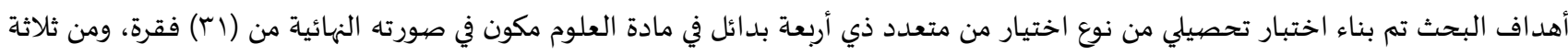

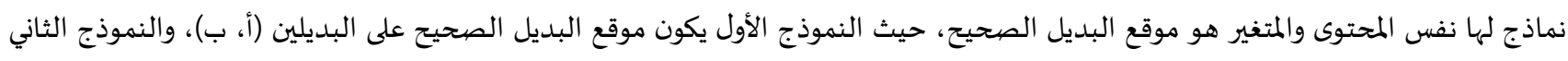

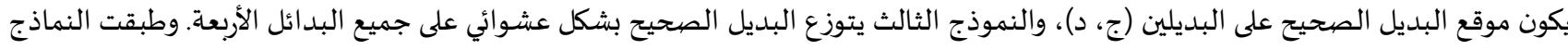

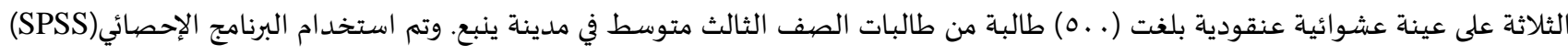

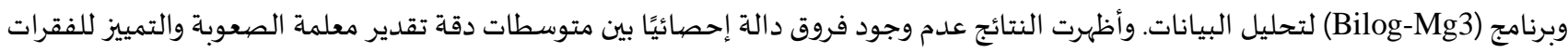

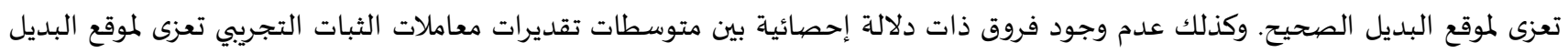

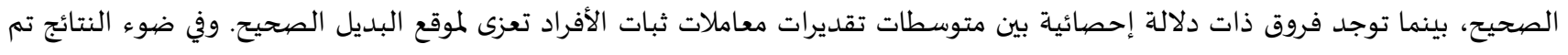

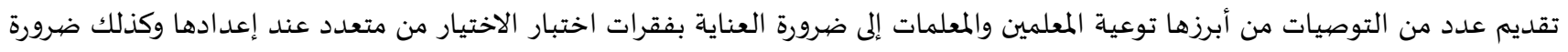
العناية بتوزيع الإجابات الصحيحة على جميع البدائل بشكل عشوائي.

الكلمات المفتاحية: موقع البديل الصحيح، اختبار اختيار من متعدد، دقة تقدير معالم الفقرة، النموذج ثنائي المعلمة، نظرية الاستجابة للفقرة. (C) (1)

المقلدمة:

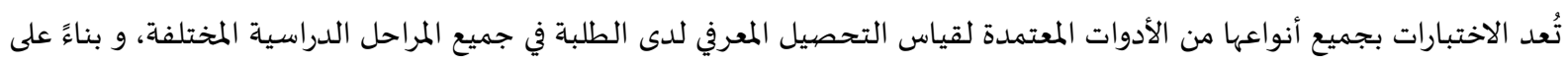

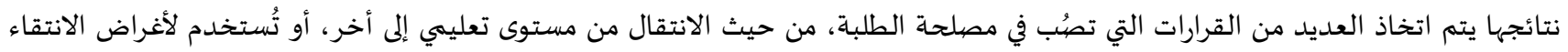

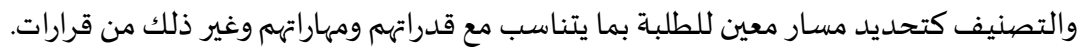

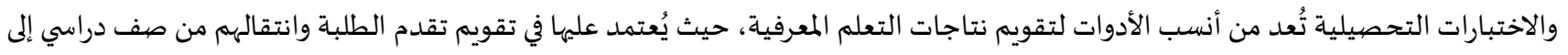

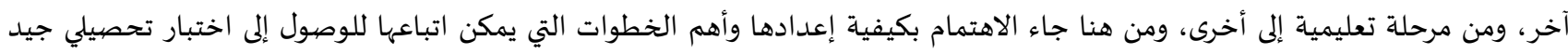

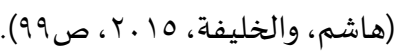

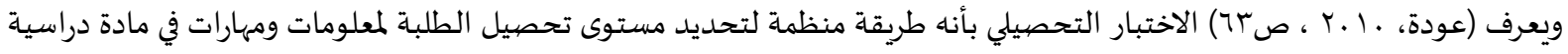

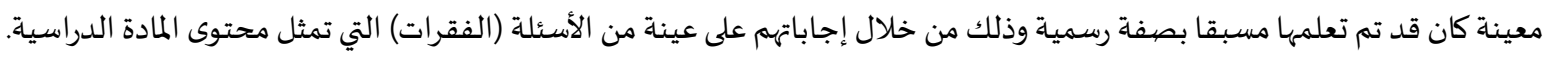

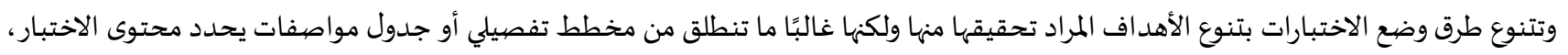

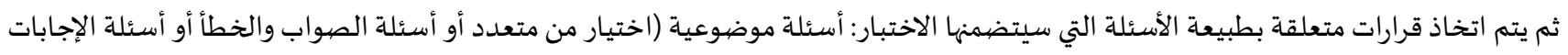
القصيرة أو أسئلة المطابقة) أو أسئلة ذات إجابات مفتوحة (مقالية) (Aiken, 1998/2007, p.37). 
وتعد الاختبارات التحصيلية من نوع الاختيار من متعدد أكثر أشكال التقويم انتشارًا في التربية ومما زاد من انتشار هذا النوع من الاختبارات

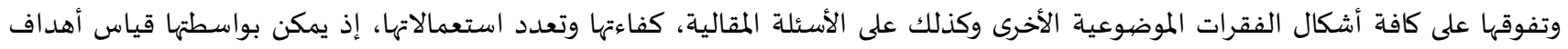

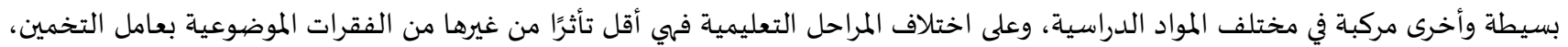

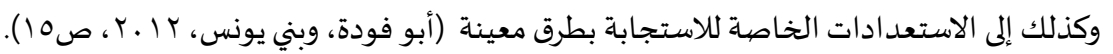

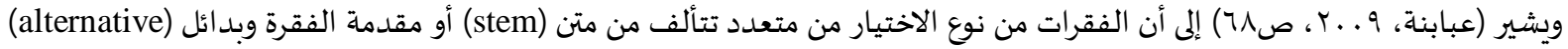

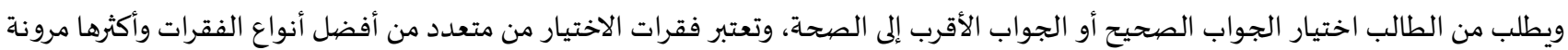
فهي لا تقتصر على قياس مستوى تذكر المعلومات بل يمكن أن توظف لقياس قدرات عقلية عليا مثل التطبيق والتحليل والتركيب.

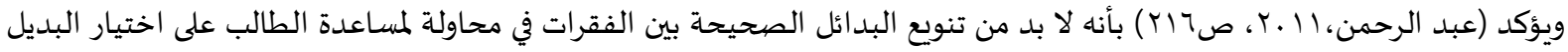

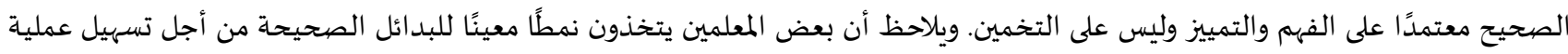
التصحيح وفي ذلك إشارة للطالب الذكي والنبيه لمعرفة الإجابات الصحيحة لبقية الفقرات، وبالتالي لن تعكس علامته حقيقة مستوى قدراته وتكون

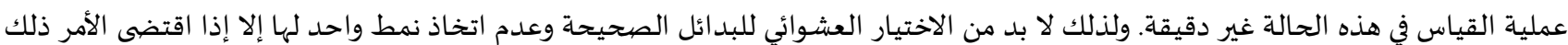
لأسباب منطقية.

ولقد أسفرت جهود العلماء في مجال القياس والتقويم إلى ظهور بعض الاتجاهات الحديثة، ومن هذه الاتجاهات نظرية الاستجابة للفقرة Item أو نظرية منحنى خصائص الفقرة Latent Trait Theory (LTT) أو نظرية السمات الكامنة Response Theory (IRT) Modern Test Theory (MTT) وقد أطلق على كل هذه الاتجاهات نظرية الاختبارات المعاصرة. Characteristic Curve Theory (ICCT)

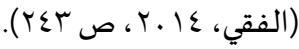
ونظرية الاستجابة للفقرة تفترض تفسير أداء الطلبة تبعًا للسمات التي لا تعتمد على المجموعة وإنما تعتمد على استجابات الطالب لفقرات

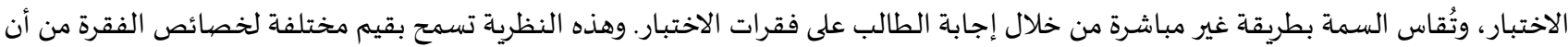

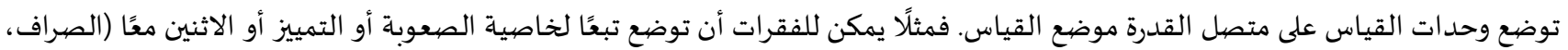
( $(\varepsilon \cdot V \cdot r \cdot) \varepsilon$

ويذكر بيكر (Baker, 2001/2010) أن نظرية الاستجابة للفقرة تنطلق منها ثلاثة نماذج رياضية لمنحنى خصائص الفقرة، وهذه النماذج تزودنا بمعادلة رياضية للعلاقة بين احتمالية الاستجابة الصحيحة للفقرة ودرجات القدرة. وكل نموذج منها يستخدم معلم Parameter أو أكثر. وهذه وهنه النماذج هي: النموذج ثلاثي المعلمة ويعتمد على معلمة الصعوبة والتمييز، والتخمين. والنموذج ثنائي المعلمة ويعتمد على معلمة الصعوبة والتمييز.

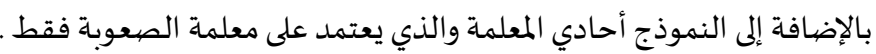
ويعتمد مستوى أداء الطالب في الاختبار على خصائص الاختبار، وخصائص الطالب، ومن خصائص فقرة الاختيار من متعدد المؤثرة في

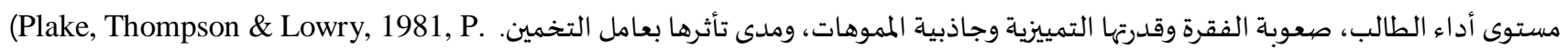

ويذكر نوادنيجو ونايبي (Nwadinigwe \& Naibi, 2013) أن صعوبة الفقرة تعتمد على موقع البديل الصحيح بالنسبة لبقية البدائل في اختبار الاختيار من متعدد. وتتأثر القدرة اللازمة للإجابة على الفقرة، بعوامل فنية تعتمد على درجة الوضوح في صياغة المتن، ومدى تجانس البدائل، ودرجة علاقتها مع متن السؤال، ومدى تحرر الفقرة بشكل عام من أي خلل في صياغتها (Lane \& Bull, 1987, P. 865-879). وأجرى كيزيك (Cizek, 1994) دراسة هدفت إلى معرفة ما إذا كان هناك أثر لإعادة ترتيب بدائل الإجابات في فقرات اختبار اختيار من

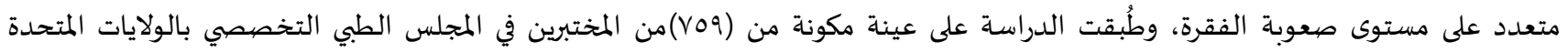

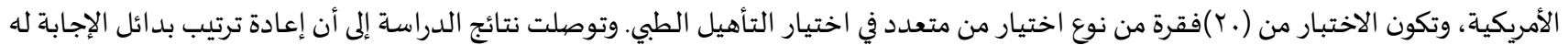

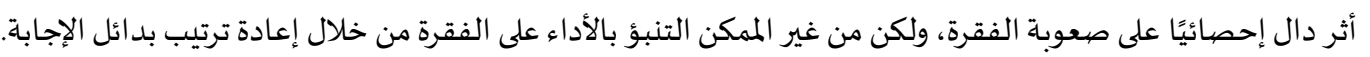

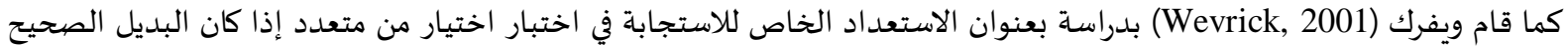

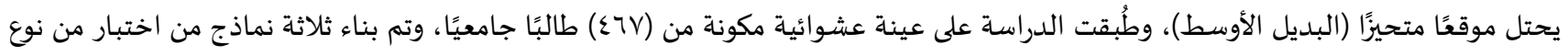

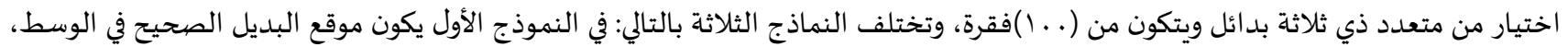
والنموذج الثاني البديل الوسط يتضيمن مموه للإجابة، والثالث موقع البديل الصحيح موزع توزيعًا عشوائيًا، وأشارت نتائج الدراسة إلى أنها إذا كان

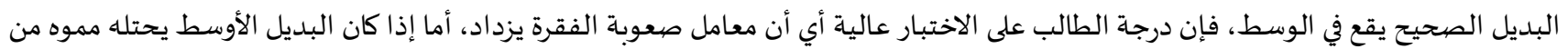

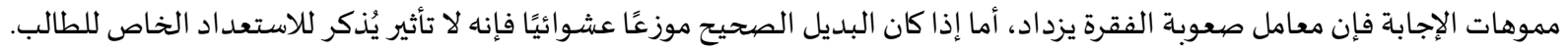




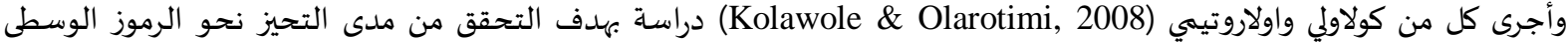

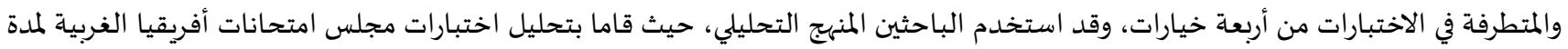

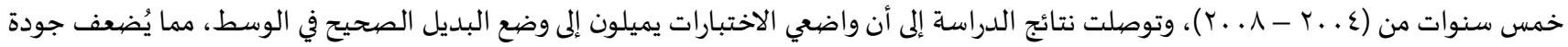
الاختبارات.

كما أجرت (الصبح، 11. (Y) دراسة هدفت إلى بيان أثر بنية فقرات الاختيار من متعدد ومستوى القدرة لدى الأفراد على دقة التقديرات

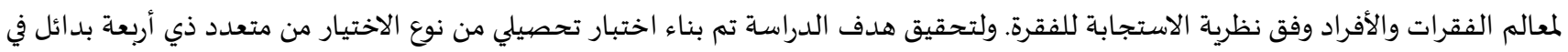

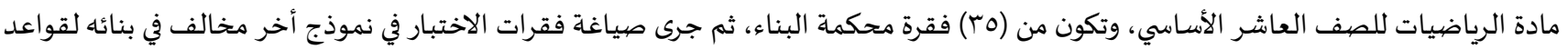

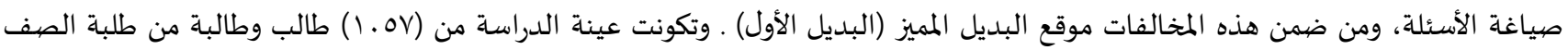

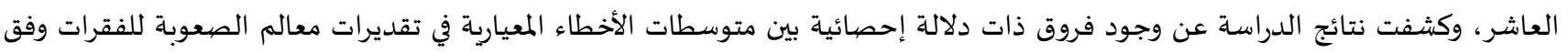

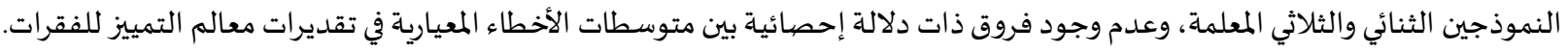

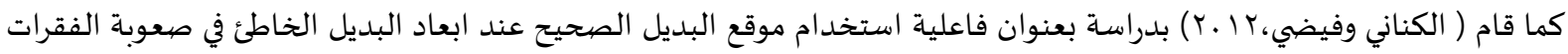

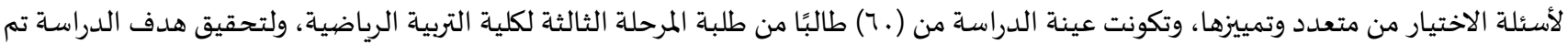

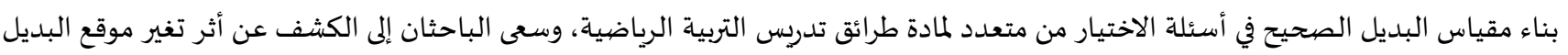

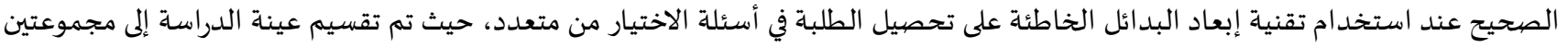

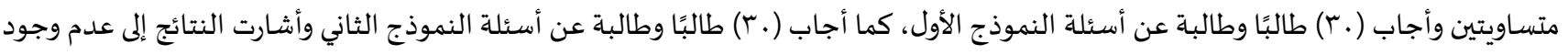

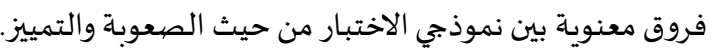

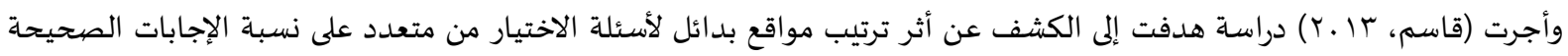

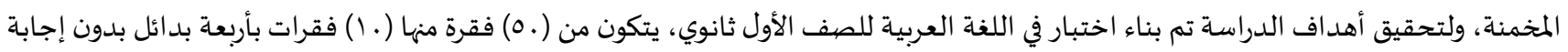

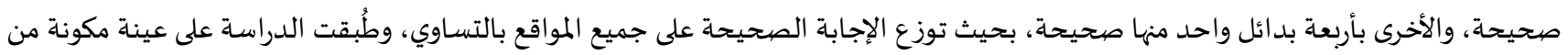

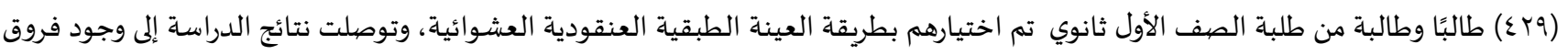

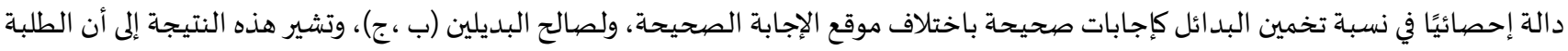

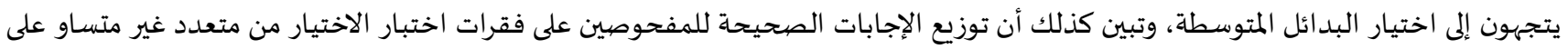
رموز الفقرات المستخدمة.

وأجرى ( الأمير، 17 ـ (Y) دراسة بعنوان الأخطاء الشائعة في بناء فقرات اختبار الاختيار من متعدد وتأثيرها على الخصائص السيكومترية

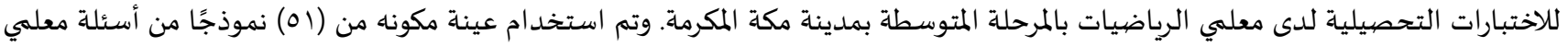

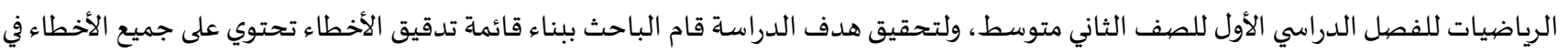

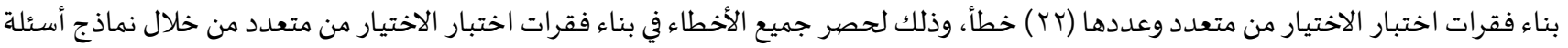

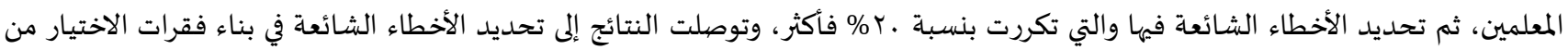

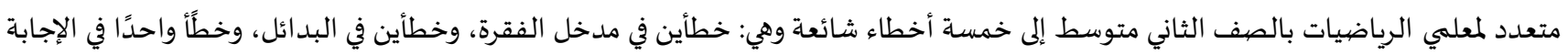
الصحيحة وهو عدم توزيع الإجابة الصحيحة توزيعًا عشوائيًا.

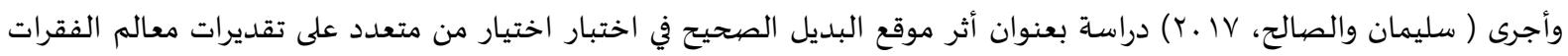

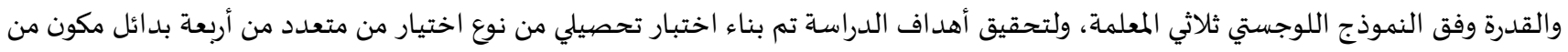

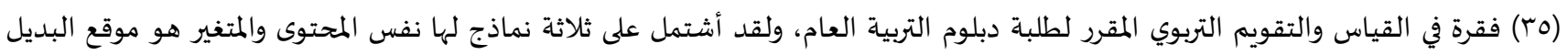

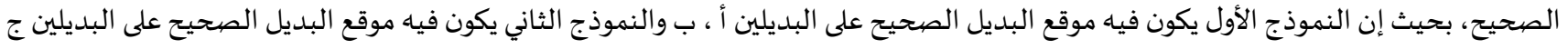

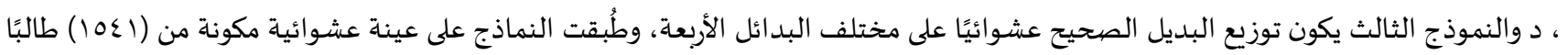

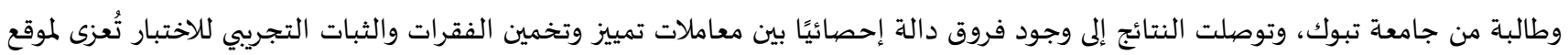

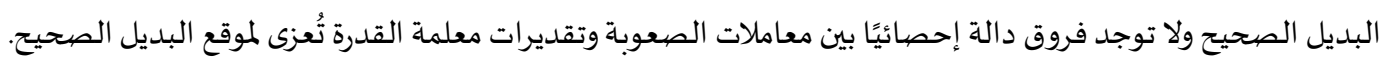

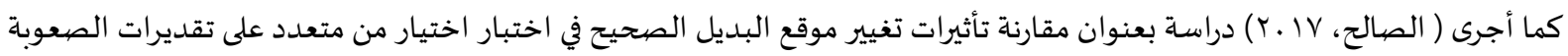

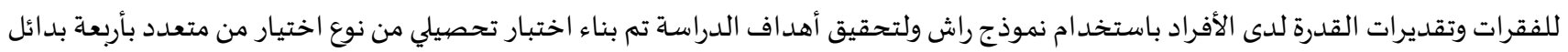

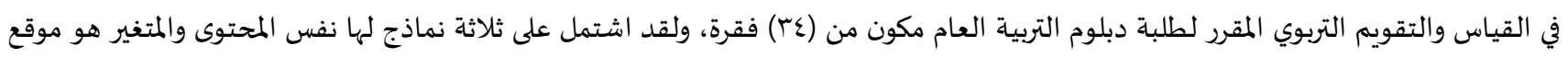

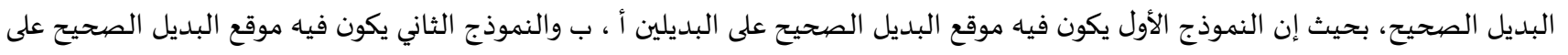


البديلين ج ، د والنموذج الثالث يكون توزيع البديل الصحيح عشوائيًا على مختلف البدائل الأربعة، وطُبقت النماذج على عينة عشوائية مكونة من (ا §ه ا) طالبًا وطالبة من جامعة تبوك، ودلت نتائج الدراسة على عدم وجود فروق دالة إحصائيًا بين المتوسطات الحسابية لمعاملات صعورية الفقرات تُعزى لموقع البديل الصحيح. ويتضح مما سبق أهمية موقع البديل الصحيح في اختبار الاختيار من متعدد، وتأثيره على تقديرات معالم الفقرة وخصائص الاختبار، ويتميز

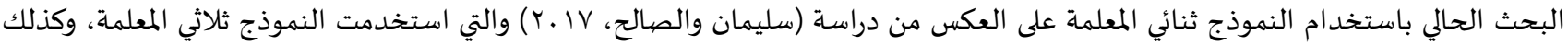
دراسة (الصالح، IV . Y) والتي استخدمت النموذج راش الأحادي المعلمة. ولقد توضح لدى الباحثين عدم وجود دراسات سابقة تناولت أثر تغيير موقع

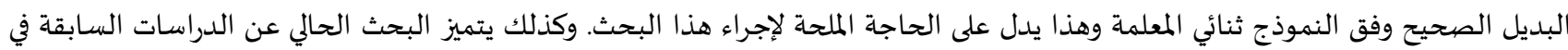

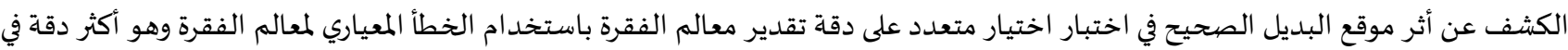
تقدير معالم الفقرة.

مشكلة البحث:

يسعى علماء القياس والمختصين بالعلوم التربوية والنفسية للتوصل الى الموضوعية في قياس سلوك الافراد واستجاباتهم، فقد بات بناء الوسيلة التي تمكن الباحث من الوصول الى التقدير الموضوعي للسلوك من الأهداف المهمة التي ينشـهـاء علماء النفس والتربويين.

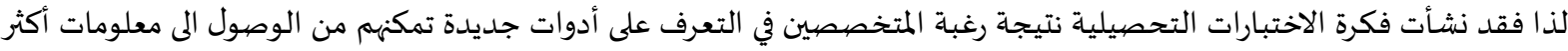

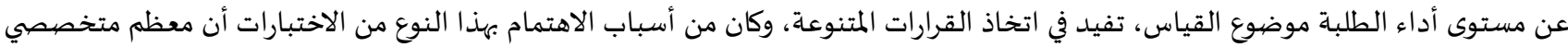
القياس والتقويم التربوي كانوا يركزون في الماضي على عدد قليل من ادوات القياس، ولم يحظ بالاهتمام ما يحتاجه المعلم من ادوات قياس لتشخيص

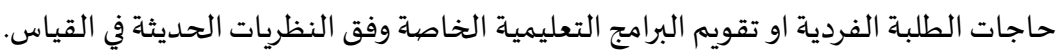
والتعليم بشكل عام، بحاجة المى توافر اختبارات تحصيلية تتمتع بدرجة مقبولة من الصدق والثبات، يمكن من خلالها قياس تحصيل الطلبة والتحقق

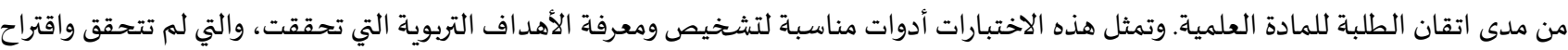

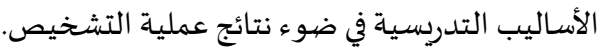
والواقع التعليمي الحالي، يعتمد بدرجة كبيرة على اختبارات التحصيل كوسيلة أساسية في تقويم الطلبة في المدارس، وهي غالباً اختبارات تقليدية يشوبها الكثير من السلبيات والأخطاء في ضوء معايير القياس والتقويم الحديث، وتبتعد من ناحية ثانية عن رسم الصيورة الصحيحة لحقيقة قدرات واستعدادات ومستويات تحصيل الطالب المراد تقويمها تربوياً.

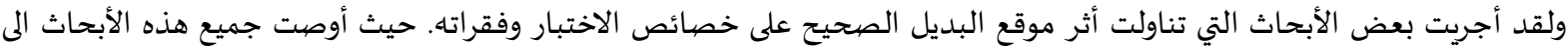
ضيرورة إجراء المزيد من الدراسات البحثية المعمقة في هذا الخصوص وفق النظريات الحديثة في القياس، كون هذا الميدان ما زال بحاجة الى المزيد من

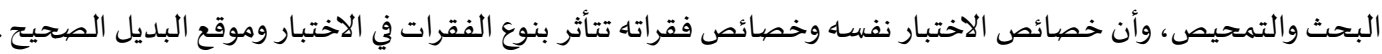
ومن هنا، فقد جاء البحث الحالي لمحاولة الكشف عن أثر موقع البديل الصحيح في اختبار اختيار من متعدد على دقة تقدير معالم الفقرة

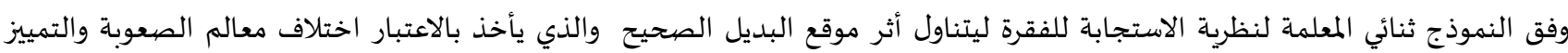

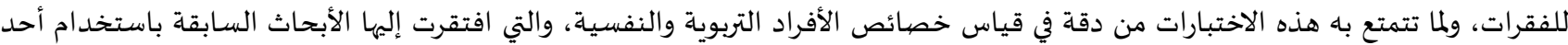

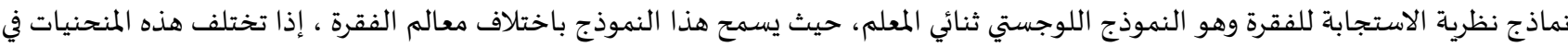
ميلها (معلمة التمييز وموقعها على متصل السمة (معلمة الصعوبة)، (Hambelton\& Swaminathan,1985, Lord,1980:241)

أسـئلة البحث:

ا. هل توجد فروق دالة إحصائيا بين متوسطات الأخطاء المعيارية في دقة تقدير معلمة الصعوبة للفقرات في اختبار اختيار من متعدد وفق نظرية

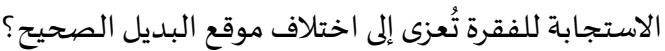

هل توجد فروق دالة إحصائيا بين متوسطات الأخطاء المعيارية في دقة تقدير معلمة التمييز للفقرات في اختبار اختيار من متعدد وفق نظرية

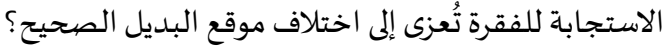
هل توجد فروق ذات دلالة إحصائية بين متوسطات تقديرات معاملات الثبات التجريبي في اختبار اختيار من متعدد وفق نظرية الاستجابة للفقرة تُعزى إلى اختلاف موقع البديل الصحيح؟ هل توجد فروق ذات دلالة إحصائية بين متوسطات تقديرات معاملات ثبات الأفراد في اختبار اختيار من متعدد وفق نظرية الاستجابة للفقرة تُعزى إلى اختلاف موقع البديل الصحيح؟ 
أهداف البحث:

يسعى البحث الحالي إلى تحقيق الأهداف التالية: ا. الكشف عن أثر موقع البديل الصحيح على دقة تقدير معلمة الصعوبة للفئ للفقرات في اختبار اختيار من متعدد وفق نظرية الاستجابة للفقرة. r. الكشف عن أثر موقع البديل الصحيح على دقة تقدير معلمة التمييز للفقرات في اختبار اختيار من متعدد وفق نظرية الاستجابة للفقرة. r. التحقق من أثر موقع البديل الصحيح على تقديرات معاملات الثبات التجريبي في اختبار اختيار من متعدد وفق نظرية الاستجابة للفقرة. ع. التحقق من أثر موقع البديل الصحيح على تقديرات معاملات ثبات الأفراد في اختبار اختيار من متعدد وفق نظرية الاستجابة للفقرة.

ا. أن البحث الحالي يسعى إلى الكشف عن تأثير اختلاف موقع البديل الصحيح في اختبار اختيار من متعدد وفق النموذج ثنائي المعلمة على دقة تقديرات معالم الفقرات وكذلك الثبات التجريبي، وثبات الأفراد.

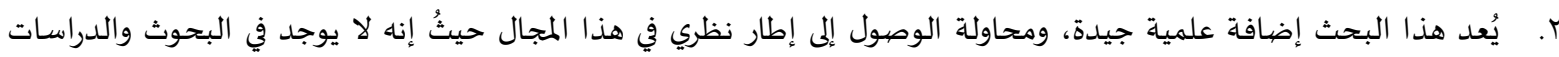
السابقة -على حد علم الباحثة- دراسة عن أثر موقع البديل الصحيح على دقة تقدير معالم الفقرة وفق النموذج ثنائي المعلمة.

ا. يوفر البحث الحالي أداة قياس يمكن الاعتماد عليها في قياس تحصيل الطالبات في مادة العلوم للصف الثالث متوسط من قبل المعلمات.

r. مساعدة الجهات المختصة في الميدان التربوي ببناء وتطوير الاختبارات التحصيلية وتحليل وتفسير نتائجها. r. قد تُسهم نتائج هذا البحث في مواصلة الباحثين بطريقة التراكم المعرفي في هذا المجال من خلال القيام بالمزيد من البحوث والدراسات المشابهة على نطاق أوسع وفي مواد دراسية أخرى.

مصطلحات البحث:

اختبار الاختيار من متعدد: " يتكون اختبار الاختيار من متعدد من المتن (Stem) أو النص أو الجذر حيث يشرح فيه المعلم المشكلة، ويتبعه

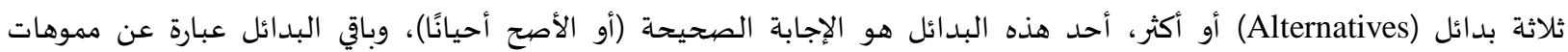
يطلب من الطالب أن يبين الإجابة الصحيحة، وقد يظهر المطلوب على شكل سؤال أو على شكل جملة مفتوحة تكتمل بالإجابة

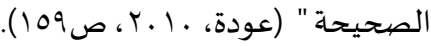
التعريف الإجرائي لاختبار الاختيار من متعدد: هو الاختبار الذي يتكون من جملة تقريرية أو سؤال، في مادة العلوم للصف الثالث متوسط، ومتبوع بعدد من البدائل؛ حيث يختار الطالب الإجابة الصحيحة من بين هذه البدائل. التعريف الإجرائي لموقع البديل الصحيح: هو موقدئ لئح رمز الإجابة الصحيحة والتي يختارها الطلبة ذوو الأداء المرتفع أكثر من الطلبة ذوي الأداء المنخفض.

(Aiken, نظرية الاستجابة للفقرة: العلاقة الوظيفية النظرية بين سلسلة للقدرات الكامنة عند الفرد وبين الإجابات على فقرات الاختبار. .1998/2007, p.95) التعريف الإجرائي لنظرية الاستجابة للفقرة: هي نظرية حديثة في مجال القياس، تعتمد على نماذج رياضية، توضح العلاقة بين القدرة و احتمال

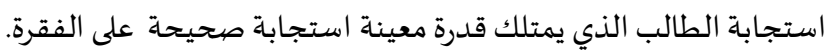

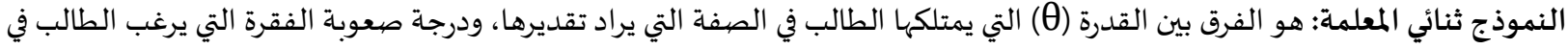

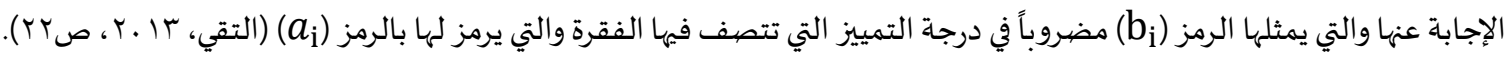

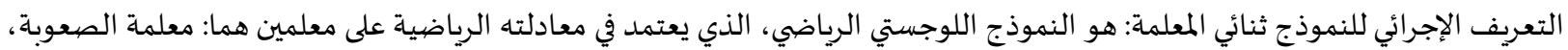
ومعلمة التمييز في حالة عدم وجود معلمة التخمين.

معلمة صعوبة الفقرة: " نقطة على مقياس القدرة عندما يكون احتمال الاستجابة الصحيحة مساويًا لـه, . " (Baker, 2001/2010, p.25).

v. 
التعريف الإجرائي لمعلمة صعوبة الفقرة: هي معلمة الفقرة التي يرمز لها بالرمز (bib) وتقع على نفس مقياس القدرة؛ لذلك يُطلق علهيا ايضاً معلمة الموقع Location Parameter.

معلمة تمييز الفقرة: هي ميل المنحنى المميز للفقرة عند نقطة الانقلاب (علام، 10 ـr، ص19179). التعريف الإجرائي لمعلمة تمييز الفقرة: هي معلمة الفقرة التي يرمز لها بالرمز (a) وهي قدرة الفقرة على التمييز بين الطلبة ذي القدرة المرتفعة وذي القدرة المنخفضية.

تقدير معالم الفقرة: هو التقدير باستخدام دالة الأرجحية العظمى (Ayala, 2009/2017, p.47). التعريف الإجرائي لتقدير معالم الفقرة: هو تقدير رقمي لمعلمة الصعوبة، ومعلمة التمييز في النموذج ثنائي المعلمة، عند افتراض معلومية تقدير معلمة القدرة. دقة تقدير معالم الفقرة: تعبير يشير إلى جودة الفقرات التي يميزها الاحتمالية الكبيرة في أن التقدير قريب من القيمة الحقيقية باستخدام الأخطاء المعيارية في التقدير (Baker, 2001). التعريف الإجرائي لدقة تقدير معالم الفقرة: هو التقدير الذي يتم باختيار تقدير الخطأ المعياري الأقل.

يقتصر البحث الحالي على الحدود التالية: حدود موضوعياة: اقتصر البحث الحالي على دقة تقدير معالم الفقرة وفق النموذج ثنائي المعلمة لاختبار من نوع اختيار من متعدد ذي أربعة بدائل، لوحدتين في مادة العلوم الوحدة الأولى (طبيعة العلم وتغيرات الأرض)، والوحدة الثانية (كيمياء المادة) للصف الثالث متوسط. حدود ديموغرافية: اقتصر البحث على طالبات الصف الثالث متوسط المنتظمات في المدارس الحكومية، والتابعة لإدارة التعليم في مدينة ينبع. حدود مكانية: تم تطبيق البحث على المدارس الحكومية للبنات، للمرحلة المتوسطة والتابعة لإدارة التعليم في مدينة ينبع.

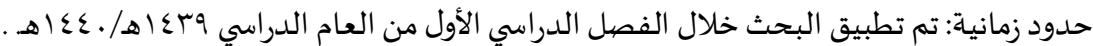

الطريقة والإجراءات: مجتمع البحث:

يتكون مجتمع البحث من جميع طالبات الصف الثالث متوسط المنتظمات في المدارس الحكومية التابعة لإدارة التعليم في مدينة ينبع للعام

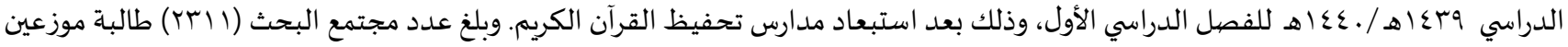
على (0ء) مدرسة، وذلك وفقًا للتقارير الإحصائية، والتي تم الحصول عليها من قسم التخطيط والتطوير بإدارة التعليم في مدينة ينبع خلال العام

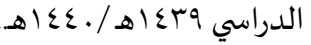
عينة البحث:

تم اختيار عينة البحث بالطريقة العشوائية العنقودية، حيث تم اختيار عدد من المدارس عشوائيًا ثم فصل من كل مدرسة ثم شعبة من كل

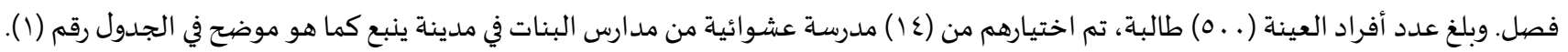
جدول(1) : توزيع عدد أفراد عينة البحث من حيث المدارس وعدد الطالبات

\begin{tabular}{|c|c|c|c|}
\hline النسبة المئوية من العينة الكلية & عدد الطالبات & اسم المدرسة & م \\
\hline$\% \mathrm{~V}, \mathrm{r}$ & 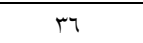 & المتوسطة الثانية & 1 \\
\hline$\% \wedge$ & $\varepsilon$. & المتوسطة الرابعة & $r$ \\
\hline$\% \wedge, \wedge$ & $\varepsilon \varepsilon$ & المتوسطة الخامسة & $r$ \\
\hline$\% \curlywedge, \uparrow$ & $\varepsilon 1$ & المتوسطة السادسة & $\varepsilon$ \\
\hline$\% 0, \varepsilon$ & Tr & المتوسطة السابعة & 0 \\
\hline$\% १, r$ & $\varepsilon 7$ & المتوسطة الثامنة & 7 \\
\hline$\% 11,7$ & 01 & المتوسطة التاسعة & $\mathrm{v}$ \\
\hline$\%\urcorner, \wedge$ & $r \varepsilon$ & المتوسطة العاشرة & $\Lambda$ \\
\hline$\% r, \varepsilon$ & IV & المتوسطة الحادية عشر & 9 \\
\hline$\% १, \varepsilon$ & $\varepsilon V$ & المتوسطة الثالثة عشر & 1. \\
\hline$\% \mathrm{r}$ & ro & المتوسطة الخامسة عشر & 11 \\
\hline
\end{tabular}

VI 


\begin{tabular}{|c|c|c|c|}
\hline$\% \uparrow, r$ & ri & متوسطة أم المؤمنين عائشة رضي الله عنها & ir \\
\hline$\% r, r$ & 11 & 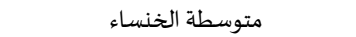 & ir \\
\hline$\%\urcorner, 7$ & r & متوسطة حفصة بنت عمر & $1 \varepsilon$ \\
\hline$\% 1 .$. & o... & المجموع & \\
\hline
\end{tabular}

لتحقيق أهداف البحث تم بناء اختبار تحصيلي من نوع اختيار من متعدد ذي أربعة بدائل في مادة العلوم للصف الثالث متوسط في الوحدتين التاليتين: الوحدة الأولى (طبيعة العلم وتغيرات الأرض)، والوحدة الثانية (كيمياء المادة)، وقد تم تتبع الخطوات والإجراءات التالية في بناء

ا. تحديد الغرض من الاختبار: تم بناء الاختبار لقياس تحصيل طالبات الصف الثالث متوسط ومعرفة مدى اكتسابهن للمعلومات والمهارات المطلوبة

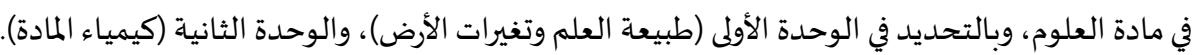
r. تحليل المحتوى الدراسي: تم تحليل المحتوى لمادة العلوم للوحدتين الأولى، والثانية، وتم صياغة الأهداف السلوكية لكل موضيوع على اهلى حده، وذلك اهلك

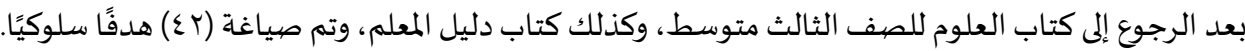

r. بناء جدول المواصفات للاختبار: حيث تم إعداد جدول المواصفات وتم فياه ربط مستويات الأهداف بمحتوى المادة الدراسية موضيوع الاختبار.

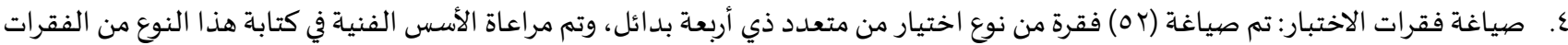

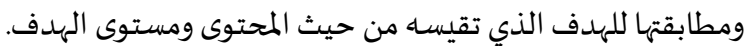

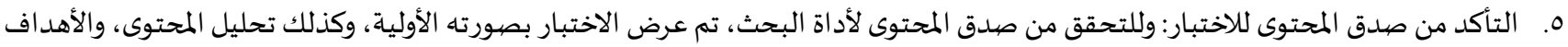

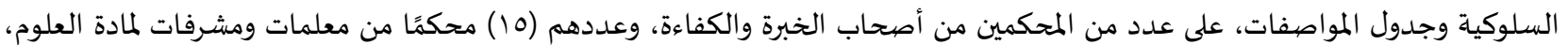

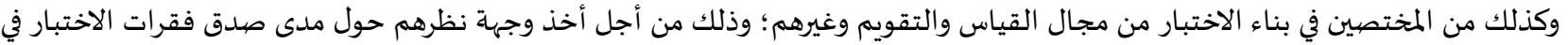

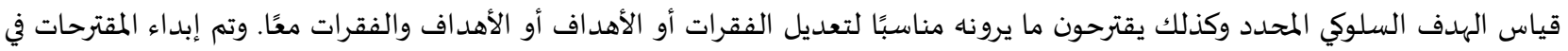

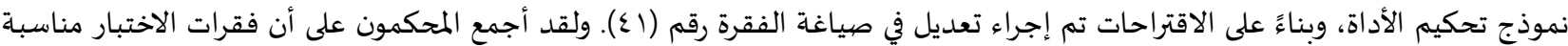
وتؤدي الغرض من الاختبار، وممثلة للمجال السلوكي الذي يتم قياسهاء.

7. إعداد الاختبار في صورته الأولية: تم إعداد الاختبار المكون من (Y (O) فقرة، وكذلك ورقة تعليمات الاختبار، والنموذج المخصصص للإجابة.

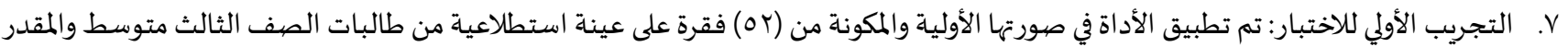

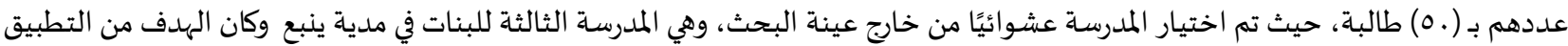

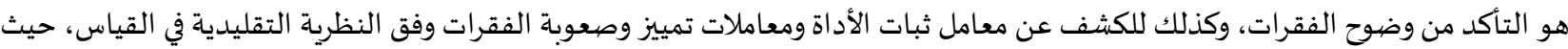

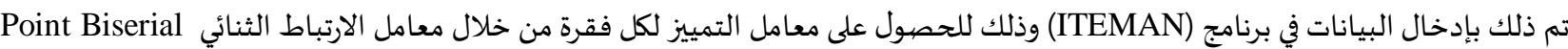
(Correlation)

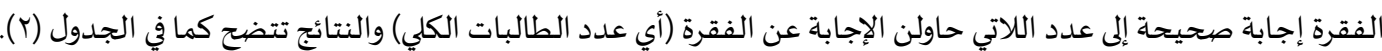

جدول (r) : معاملات الصعوبة والتمييزلفقرات الاختبارللعينة الاستطلاعية وفق النظرية التقليدية

\begin{tabular}{|c|c|c|c|c|c|c|c|c|}
\hline معامل التمييز & معامل الصعوبة & رقم الفقرة & معامل التمييز & معامل الصعوبة & رقم الفقرة & معامل التمييز & معامل الصعوبة & رقم الفقرة \\
\hline$\cdot, \ldots$ &., 77 & ro &.,$r_{1}$ &.,$\Gamma \wedge$ & 11 & . &., 01 & 1 \\
\hline$\cdot, \leqslant 9$ &., 07 & רי & $\cdot, . \varepsilon$ &., $0 \leqslant$ & 19 &.,$T V$ &., 0 & r \\
\hline - &.,$r$. & rV &.,$Y T$ &., 7 . & r. &.,$T Y$ & $\cdot, \wedge$ & $r$ \\
\hline., $11-$ &.,$r$. & r &., 79 &., $0 \varepsilon$ & YI &.,$Y \varepsilon$ &., 97 & $\varepsilon$ \\
\hline., 71 &., 77 & $r 9$ &.,$Y \varepsilon$ &., $\mathrm{V} 7$ & Tr &.,$\Gamma \wedge$ &., $\mathrm{V7}$ & 0 \\
\hline.,$\leqslant q$ &.,$v \varepsilon$ & $\varepsilon$. &., $\mathrm{OV}$ &., 0 & rr &., $4 q$ & $\cdot, \vee$. & 7 \\
\hline.,.$\wedge$ &., $0 \varepsilon$ & $\varepsilon 1$ &., 10 &., $0 \varepsilon$ & $T \varepsilon$ &.,$\Gamma \varepsilon$ & $\cdot, \wedge$ & V \\
\hline.,$\Gamma \wedge$ &., $0 \mathrm{r}$ & $\varepsilon r$ & $\cdot, \cdot r_{-}$ & $\cdot, \varepsilon$. & ro & . & $\cdot, \mathrm{r}$ & $\Lambda$ \\
\hline$\cdot, r_{1}$ & . & $\varepsilon r$ & , ro &., 7 & r &., .0 &., $7 \Lambda$ & 9 \\
\hline., $0 \leqslant$ &., $7 \Lambda$ & $\varepsilon \varepsilon$ &.,$\mu$ &., $0 \varepsilon$ & TV &.,$r \varepsilon$ &.,$Y Y$ & 1. \\
\hline., 1. &.,$\varepsilon r$ & «o &., 11 &., 0 & rM &.,$\cdot r$ &., $\mathrm{r}$ & 11 \\
\hline
\end{tabular}




\begin{tabular}{|c|c|c|c|c|c|c|c|c|}
\hline , TO & $\cdot, V \varepsilon$ & $\sum 7$ &., 07 & •, Ү. & rq &.,${ }^{\prime}$ & rT, & IT \\
\hline$\cdot, 1 .-$ & $\cdot,{ }^{\prime}$ & $\varepsilon V$ &., $19-$ & $\cdot, r \cdot$ & $r$. & $\cdot, r \mid$ &.,$\varepsilon r$ & 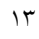 \\
\hline., 1. &.,$Y \varepsilon$ & $\varepsilon \wedge$ &.,$r \varepsilon$ & ., $\{7$ & r & $\cdot, \cdot r$ & $\cdot, \leqslant \varepsilon$ & $1 \varepsilon$ \\
\hline$\cdot, 1 \Gamma-$ & $\cdot, \varepsilon r$ & $\varepsilon 9$ & $\cdot, r V$ & $\cdot, V T$ & rT & $\cdot, \varepsilon \varepsilon$ & $\cdot, V \varepsilon$ & 10 \\
\hline$\cdot, \cdot \wedge$ & $\cdot, T \varepsilon$ & 0. &., , & $\cdot, 7 \wedge$ & rr & $\cdot, \cdot 1-$ & $\cdot, 71$ & 17 \\
\hline ., זq &., 07 & 01 &.,$T V$ & ., & $r \varepsilon$ & . & דר & IV \\
\hline - ro- & . & or & & & & & & \\
\hline •, YT & & ساب & & & .,Or & & سابي لم & \\
\hline
\end{tabular}

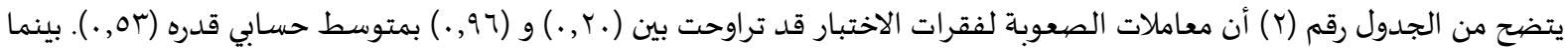

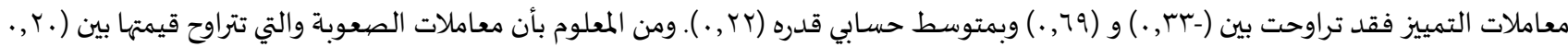

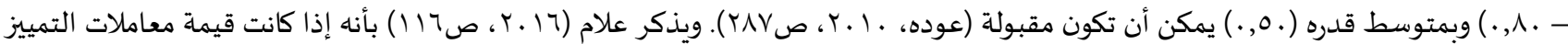

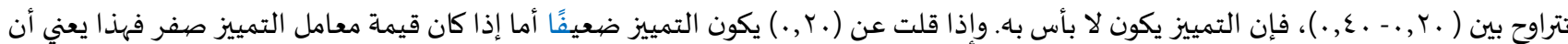

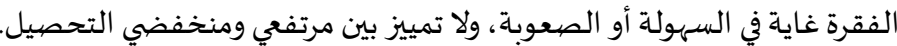

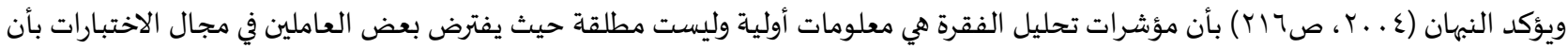

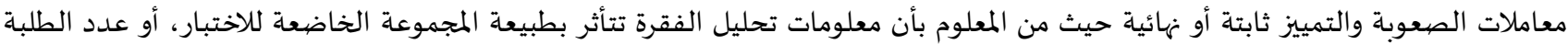

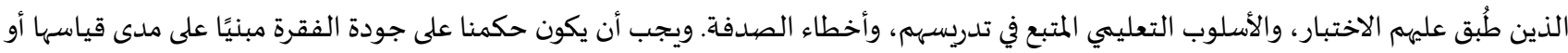

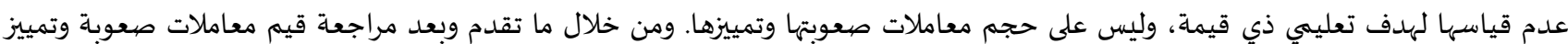
الفقرات، يتضح لنا ضرورة حذف الفقرات التالية:

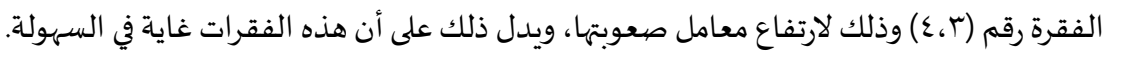

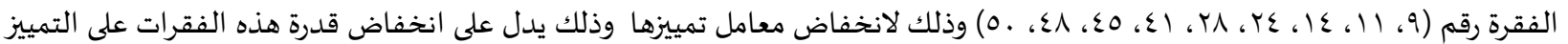

الفقرة رقم (ro) وذلك لأن قيمة معامل تمييزها يساوي صفر، وذلك يدل على أن الفقرة لا تُميز بين الطالبات ذوات التحصيل المرتفع والمنخفض.

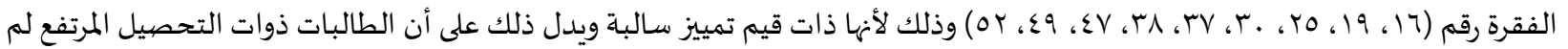

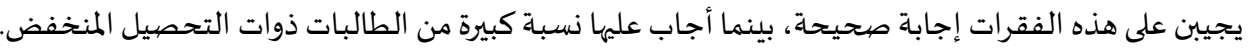

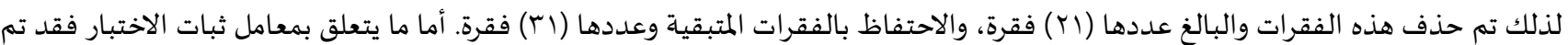

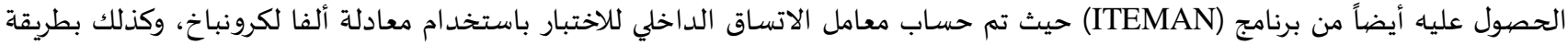

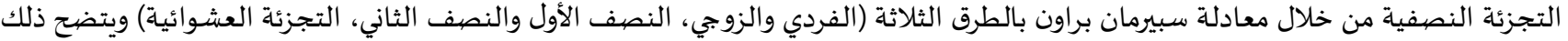

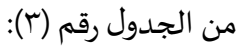

\begin{tabular}{|c|c|c|}
\hline قيمة معامل الثبات & \multicolumn{2}{|c|}{ الطريقة } \\
\hline., $\mathrm{VV}$ & \multicolumn{2}{|c|}{ معامل ألفا لكرونباخ } \\
\hline$\cdot, \mathrm{VA}$ & $\begin{array}{c}\text { الفردي والزوجي } \\
\text { S-B Odd-Even }\end{array}$ & التجزئة النصفية \\
\hline$\cdot, \mathrm{V} 7$ & النصف الأول والنصف الثاني & \\
\hline$\cdot, 71$ & $\begin{array}{l}\text { التجزئة العشوائية } \\
\text { S-B Random }\end{array}$ & \\
\hline
\end{tabular}

جدول (r): قيم معاملات الثبات للاختبارللعينة الاستطلاعية

ويتضح من الجدول السـابق، بأن قيم معاملات الثبات بالطرق المختلفة تُعد مناسبة ومقبولة وتخدم أغراض البحث. ᄉ. تطبيق الاختبار بصيورته النهائية: بعد تحليل فقرات الاختبار للعينة الاستطلاعية وحذف الفقرات غير المناسبة، تم إعداد الاختبار في صورته النهائية والمكون من (ابr) فقرة، حيث تم إعداد ثلاثة نماذج من الاختبار لها نفس المحتوى والمتغير هو موقع البديل الصحيح، بحيث إن النموذج الأول يكون فياء موقع البديل الصحيح على البديلين (أ ، ب)، والنموذج الثاني يكون فياء موقع البديل الصحيح على البديلين (ج ، د) والنموذج الثالث يكون

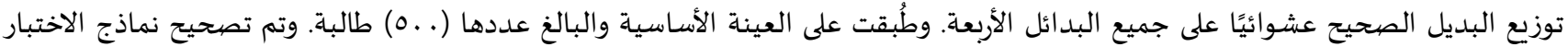


باستخدام برنامج (Zip Grade) وتم إدخال بيانات كل نموذج على حده إلى ذاكرة الحاسوب وذلك لاستخدامها في البرمجية الإحصائية (SPSS)، وكذلك برنامج (Bilog-Mg3) من أجل تحليل بيانات البحث. باست

متغيرات البحث:

المتغير المستقل: موقع البديل الصحيح وله ثلاثة مستويات.

المتغير التابع: دقة تقديرات معالم الفقرة، والثبات التجريبي، وثبات الأفراد.

الأسـاليب الإحصائية المستخدمة:

تم استخدام برنامج (ITEMAN) لحسباب ما يلي: ا ب. استخراج معامل صعوبة الفقرة بالنظرية التقليدية للقياس.

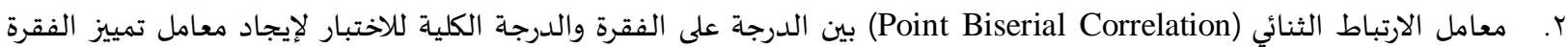
بالنظرية التقليدية للقياس.

r. معامل ثبات الاختبار بالطرق المختلفة مثل طريقة ألفا لكرونباخ (Alpha)، وطريقة التجزئة النصفية (Split-Half). وتم استخدام البرمجية الإحصائية (SPSS) لحساب ما يلي: ا. التحليل العاملي الاستكشافي للتحقق من افتراض أحادية البعد للاختبار. r. اختبار تحليل التباين الأحادي (One Way ANOVA) للكشف عن دلائلة التائة الفروق بين المتوسطات الحسابية لدقة تقدير معالم الفقرة باختلاف موقع البديل الصحيح.

استخدام البرنامج الإحصائي (Bilog-Mg3) لحساب التالي:

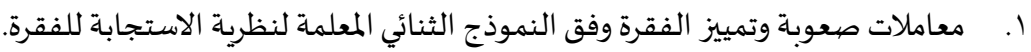

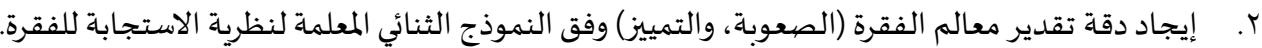
r. اختبار مريع كاي لحسن المطابقة للكشف عن مدى مطابقة الفقرات للنموذج اللوجستي ثنائي المعلمة. عرض ومناقشاة نتائج البحث: عرض نتائج البحث: أولاً: النتائج المتعلقة بالتحقق من افتراضـات نظرية الاستجابة للفقرة (النموذج ثنائي المعلمة).

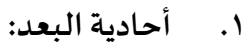

من افتراضات نظرية الاستجابة للفقرة، أن تكون استجابة الفرد على الفقرة تقيس عاملًا واحدًا وليس عدة عوامل، أي تقيس سمة معينة بذاتها. وتم التحقق من افتراض أحادية البعد باستخدام برنامج (SPSS)، من خلال التحليل العاملي الاستكشافي (Factor Analysis) بطريقة

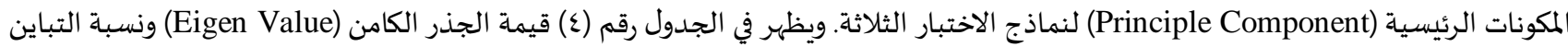
المفسر (Explained Variance) للعامل الأول والثاني، وكذلك ناتج قسمة الجذر الكامن للعامل الأول على العامل الثاني، وذلك للنماذج الثلاثة.

جدول (ع): قيم الجذور الكامنة ونسب التباين المفسروالتر اكمي لنماذج الاختبار الثلاثة

\begin{tabular}{|c|c|c|c|c|c|}
\hline الجذر الكامن للعامل الثاني الكامن للعامل الأول & التباين المفسر التراكمي & التباين المفسر & الجذر الكامن & العامل & النموذج \\
\hline \multirow[t]{2}{*}{$r, \neg \varepsilon$} & $\mid r, 4 r$ & $\mid \varepsilon, \pi r$ & $\{, 0 \varepsilon$ & الأول & \multirow{2}{*}{ الأول } \\
\hline & $r ., \mid V$ & $0,0 \varepsilon$ & I,VT & الثاني & \\
\hline \multirow[t]{2}{*}{$r, r}$. & $|\Lambda, \Lambda\rangle$ & $\mid \Lambda, \wedge \Lambda$ & 0,10 & الأول & \multirow{2}{*}{ (البديل الصحيح على ج و د) } \\
\hline & $r \varepsilon, Y \wedge$ & 0,19 & $1, \Lambda r$ & الثاني & \\
\hline \multirow[t]{2}{*}{$r, \Sigma \varepsilon$} & 10,90 & 10,90 & $\varepsilon, 90$ & الأول & \multirow{2}{*}{ 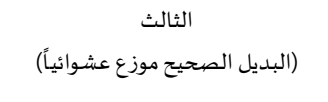 } \\
\hline & $r r, \Sigma 9$ & $7,0\}$ & $r, \cdot r$ & الثاني & \\
\hline
\end{tabular}


يتبين من الجدول رقم (ع) أن ناتج قسمة الجذر الكامن للعامل الأول على الثاني في النماذج الثلاثة كانت أكبر من (Y)، مما يدل على وجود

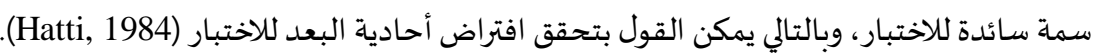
ومن خلال مخطط سكري (Scree Plot) للعوامل مع الجذور الكامنة، والذي يتضح في الأشكال رقم (1)، (r)، (r) يتبين أن الجذر الكامن للعامل الأول يتميز بشكل كبير عن الجذور الكامنة لبقية العوامل وذلك للنماذج الثلاثة، وهذا مؤشر ايضًا على أحادية البعد لبيانات الاختبار

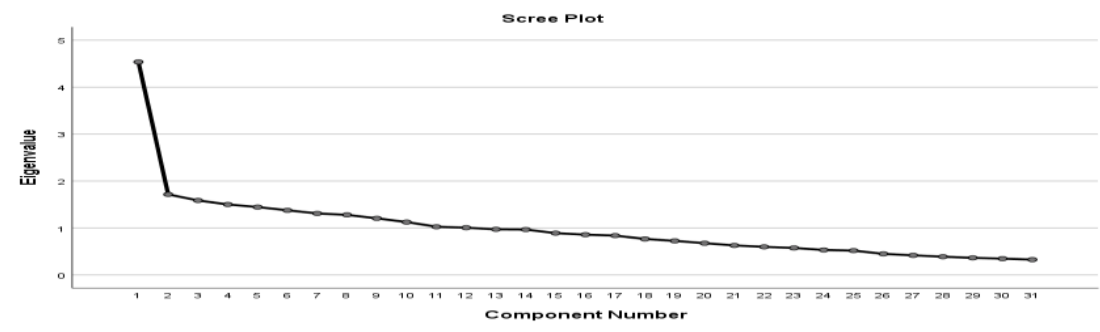

شكل (1): مخطط سكري لقيم الجذور الكامنة للعوامل في النموذج الأول

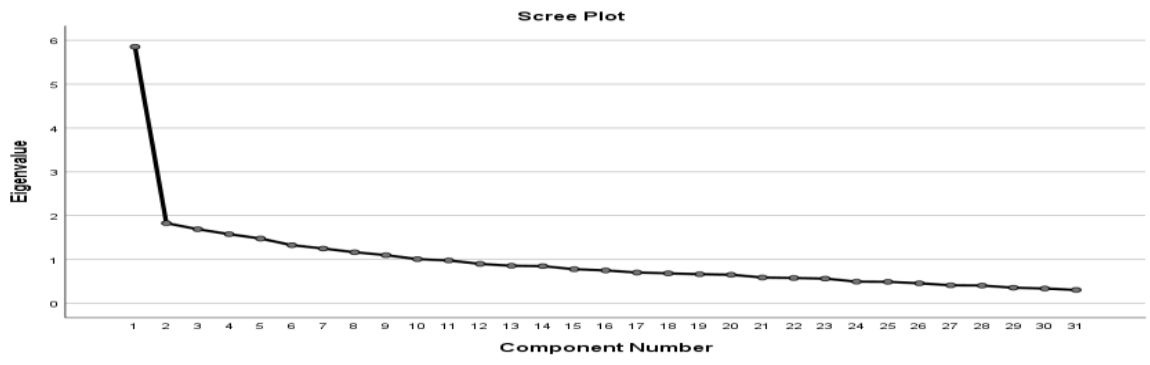

شكل (ץ): مخطط سكري لقيم الجذور الكامنة للعوامل في النموذج الثاني

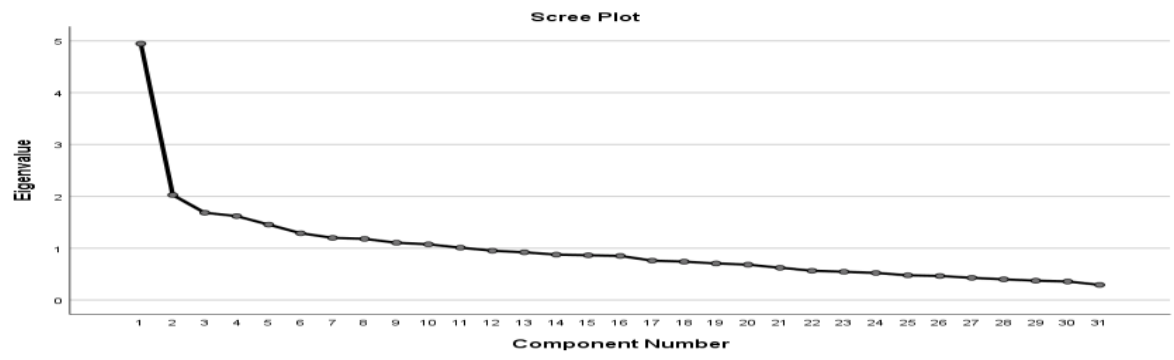

شكل (r): مخطط سكري لقيم الجذور الكامنة للعوامل في النموذج الثالث

ويتضح من الأشكال السابقة رقم (1)، (Y)، (Y) أن افتراض أحادية البعد قد تحقق للنماذج الثلاثة حيث يتبين من خلال الرسم البياني باستخدام أن قيمة الجذر الكامن للعامل الأول كانت مرتفعة نسبيًا عن بقية العوامل والتي تبدو متقاربة، ويتضح ذلك بشكل أكبر في النموذج مانج

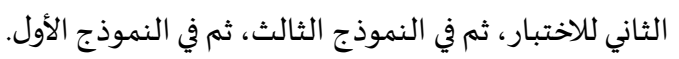
r. الاستقلال الموضعي:

ويقصد بذلك أن إجابة الطالب على الفقرة لا تتأثر بإجابته عن فقرة أخرى والعامل الوحيد المؤثر على احتمال الاجابة عن الفقرة هو مقدار

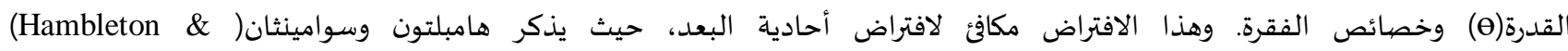
أحادر Swaminathan,1985 أنه إذا تحقق افتراض أحادية البعد يعني تحقق افتراض الاستقلال الموضعي. ويتضح من خلال النتائج السابقة تحقق افتراض أحادية البعد وبالتالي تحقق افتراض الاستقلال الموضعي.

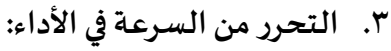

ويقصد بذلك إعطاء الطلبة الوقت الكافي للإجابة على فقرات الاختبار. ولقد تم تحقق هذا الافتراض بحيث تم الانتهاء من الاختبار لجميع

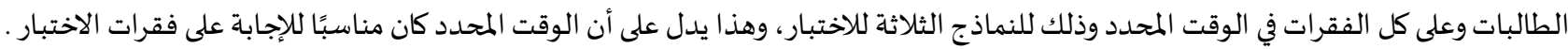


ثانياً: التحقق من مطابقة الأفراد والفقرات للنموذج ثنائي المعلمة.

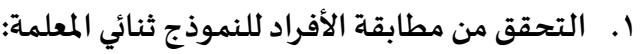

والمقصود بذلك تحديد ما إذا كان الطالب يتصرف بطريقة متوافقة مع النموذج أو لا. وبشكل أكثر تحديدًا فالأفراد غير المتطرفين لا يستبعدون من النموذج، حيث إن المفحوص المتطرف يكون قد حصل على الدرجة الخام صفر، أو الدرجة الكاملة وبالتالي يُستبعد من النماذج ويُعد غير مطابق للنموذج (Ayala,2009 /2017, p.62). وبهدف التحقق من درجة مطابقة الأفراد للنموذج ثنائي المعلمة، تم إدخال البيانات الخاصة باستجابة أفراد عينة البحث ( . .0) طالبة إلى

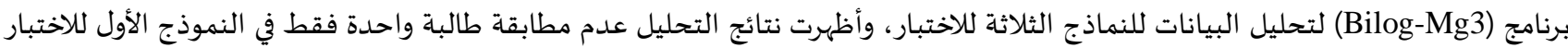
(موقع البديل الصحيح على البديلين أو ب)، وكذلك عدم مطابقة طالبة واحدة فقط في النموذج الثاني للاختبار (موقع البديل الصحيح على البديلين ج و د)، بينما تبين عدم مطابقة طالبتين في النموذج الثالث للاختبار (موقع البديل الصحيح عشوائيًا). وبالتالي تم استبعاد استجاباتيات الطالبات غئير

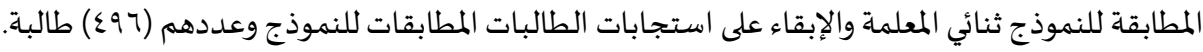

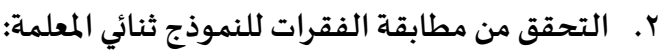

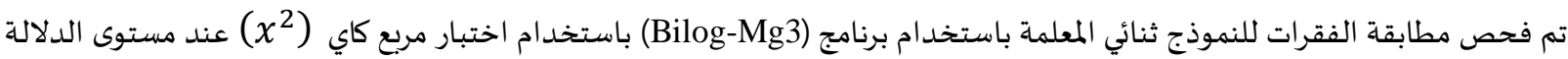
(1 , . ) وذلك للنماذج الثلاثة للاختبار وكانت النتائج كالتالي:

جدول (0): نتائج مطابقة الفقرات للنموذج ثنائي المعلمة في النموذج الأول للاختبار

\begin{tabular}{|c|c|c|c|c|c|c|c|c|}
\hline مستوى دلالة كاي & قيمة كاي & رقم الفقرة & مستوى دلالة كاي & قيمة كاي تربيع & رقم الفقرة & مستوى دلالة كاي & قيمة كاي تربيع & رقم الفقرة \\
\hline., $1 \varepsilon$ & 11,1 & YI & $\cdot, \cdot V$ & $\mid \varepsilon, \varepsilon$ & 11 & $\cdot, \mathrm{NT}$ & $r, r$ & 1 \\
\hline$\cdot, \cdot V$ & $1 r, 1$ & TY &., 49 & $v, r$ & IT & $\cdot, \wedge \varepsilon$ & $r, 0$ & $r$ \\
\hline$\cdot, \cdot r$ & $\mid V, \varepsilon$ & r & $\cdot, \cdot \varepsilon$ & $1 \varepsilon, 0$ & $1 \pi$ &., 199 & $r, q$ & $r$ \\
\hline., 90 & 1,7 & $T \varepsilon$ & , $7 \varepsilon$ & $r, 0$ & $1 \varepsilon$ & $\cdot, 91$ & 1,0 & $\varepsilon$ \\
\hline$\cdot, \wedge \Lambda$ & $r, \varepsilon$ & ro &.,$\leq 0$ & $\varepsilon, V$ & 10 &., 00 & $\varepsilon$, & 0 \\
\hline$\cdot, \wedge\rceil$ & $1, r$ & Y & $\cdot, \leqslant 0$ & $7, \Lambda$ & 17 &.,$\Gamma \varepsilon$ & $r, \varepsilon$ & 7 \\
\hline$\cdot, \mathrm{VV}$ & $\varepsilon, 1$ & TV & $\cdot, 97$ & $r,$. & IV &.,$r q$ & $9, \mathrm{~V}$ & V \\
\hline., 17 & $1 ., 0$ & $r \Lambda$ & $\cdot, 9 r$ & $r, r$ & 11 & r & 7,9 & $\wedge$ \\
\hline . 77 & $0,$. & rq & $\cdot, V Y$ & $\varepsilon, 0$ & 19 & $\cdot, \cdot \wedge$ & $1 Y, T$ & 9 \\
\hline rT, & $\Lambda, r$ & $r$. & $\cdot, \leqslant \wedge$ & 7,0 & $r$. & $\cdot, \wedge \varepsilon$ & $r, 1$ & 1. \\
\hline$\cdot, 10$ & $r, r$ & ri & & & & & & \\
\hline
\end{tabular}

يتضح من الجدول رقم (0) مطابقة جميع فقرات الاختبار في النموذج الأول للاختبار (موقع البديل الصحيح على البديلين أو ب) للنموذج ثنائي

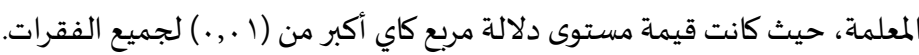


جدول (7): نتائج مطابقة الفقرات للنموذج ثنائي المعلمة في النموذج الثاني للاختبار

\begin{tabular}{|c|c|c|c|c|c|c|c|c|}
\hline مستوى دلالة كاي & قيمة كاي & رقم الفقرة & مستوى دلالة كاي & قيمة كاي & رقم الفقرة & مستوى دلالة كاي & قيمة كاي تربيع & رقم الفقرة \\
\hline ., हT & $\mathrm{V}, \mathrm{l}$ & rI & $\cdot, 10$ & $\varepsilon, 1$ & 11 &.,$q \Gamma$ & 1,9 & 1 \\
\hline., 99 & $1, \varepsilon$ & rr &., 0 . & $7, r$ & IT &., $9 v$ & I,V & r \\
\hline., 70 & $7,$. & rr &., 1. & Ir, & Ir &., 97 & $1, \varepsilon$ & $r$ \\
\hline., 90 & 1,7 & $T \varepsilon$ &., $9 r$ & $1, \lambda$ & $1 \varepsilon$ &., $0 \mathrm{~V}$ & $r, q$ & $\varepsilon$ \\
\hline., 71 & $\varepsilon, \Lambda$ & ro & $\cdot, 9$ & $r, q$ & 10 &., 19 & 7,1 & 0 \\
\hline , ro & $0, \varepsilon$ & rY &., 90 & $r, 1$ & 17 & $\cdot, \mathrm{V} 7$ & $r, 7$ & 7 \\
\hline . & 1,0 & TV & צ & $0, r$ & IV & $\cdot, 9$ & $r, 0$ & V \\
\hline., 7 & 0,0 & ru & r & 7,1 & 11 &., 09 & 0,0 & 1 \\
\hline., $\mathrm{V} 7$ & $r, 7$ & rq & .,9ז & 1,9 & 19 &., 17 & $\Lambda, 9$ & 9 \\
\hline., 01 & $\varepsilon, \Lambda$ & $r$. &.,$\Sigma V$ & $v, 7$ & $r$. & $\cdot, 91$ & $1, r$ & 1. \\
\hline .,0 & $\varepsilon, 1$ & rI & & & & & & \\
\hline
\end{tabular}

يتضح من الجدول رقم (7) مطابقة جميع فقرات الاختبار في النموذج الثاني للاختبار (موقع البديل الصحيح على البديلين ج و د) للنموذج ثنائي

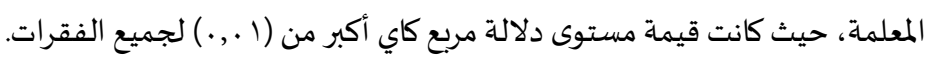

جدول(V): نتائج مطابقة الفقرات للنموذج ثنائي المعلمة في النموذج الثالث للاختبار

\begin{tabular}{|c|c|c|c|c|c|c|c|c|}
\hline مستوى دلالة كاي & قيمة كاي & رقم الفقرة & مستوى دلالة كاي & قيمة كاي & رقم الفقرة & مستوى دلالة كاي & قيمة كاي تربيع & رقم الفقرة \\
\hline$\cdot, \wedge \varepsilon$ & $r, \varepsilon$ & $r$ & , हr & $\mathrm{v},$. & 11 &., 90 & 1,1 & 1 \\
\hline., 00 & $\varepsilon$, & Tr &., 97 & $r,$. & Ir & 更 & 7,9 & $r$ \\
\hline$\cdot, \lambda 1$ & $r, v$ & rr &., $1 V$ & $1 ., r$ & ir & $\cdot, \mathrm{V} 7$ & 1,1 & $r$ \\
\hline., .0 & $9, r$ & $r \varepsilon$ &., $\mathrm{Vq}$ & $r, \varepsilon$ & $1 \varepsilon$ &., 17 & $1, r$ & $\varepsilon$ \\
\hline., 19 & $7, r$ & ro & $\cdot, 9 \varepsilon$ & $1, r$ & 10 &., 01 & $r, r$ & 0 \\
\hline$\cdot, r$. & $\varepsilon, V$ & $r 7$ &., .0 & $1 \varepsilon, r$ & 17 & $\cdot, 94$ &., 9 & 7 \\
\hline., 99 & $1, r$ & TV &., 99 &., 0 & IV & $\cdot, \lambda \mathrm{V}$ & $r, 1$ & $\mathrm{v}$ \\
\hline., 7 & 0,0 & ru & $\cdot, 97$ & $r,$. & 11 & $\cdot, 71$ & $r, 1$ & 1 \\
\hline., 00 & $\varepsilon,$. & rq &., 1. & $9, r$ & 19 &., 49 & $0, r$ & 9 \\
\hline$\cdot, \wedge$ & 1,7 & $r$. &., 11 & $1 ., \varepsilon$ & r. &., 77 & $r, r$ & 1. \\
\hline., $1 \varepsilon$ & $\Lambda, \varepsilon$ & $r$ & & & & & & \\
\hline
\end{tabular}

يتضح من الجدول رقم (V) مطابقة جميع فقرات الاختبار في النموذج الثالث للاختبار (موقع البديل الصحيح موزع عشوائيًا) للنموذج ثنائي

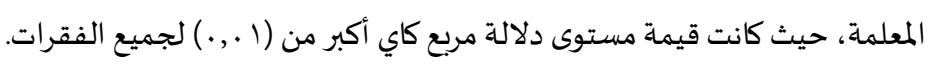

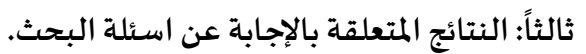
السؤال الأول: هل توجد فروق دالة إحصائيا بين متوسطات الأخطاء المعيارية في دقة تقدير معلمة الصعوبة للفقرات في اختبار اختيار من متعدد وفق بإِ

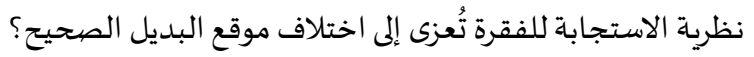

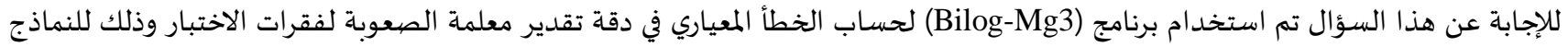
الثلاثة للاختبار، كما هو موضح في الجدول رقم (^) والذي يوضح كذلك تقديرات معلمة الصعوبة. وحساب المتوسط الحسابي والانحراف المعياري لدقة تقدير معلمة الصعوبة وذلك للنماذج الثلاثة للاختبار، كما هو موضح في الجدول رقم (9) والذي يوضح أيضًا المتوسط الحسابي والانحراف 
جدول (^): تقديرات قيم معلمة الصعوبة والأخطاء المعيارية في دقة تقديرها لفقرات الاختبارللنماذج الثلاثة

\begin{tabular}{|c|c|c|c|c|c|c|}
\hline \multicolumn{2}{|c|}{ النموذج الثالث (البديل الصحيح موزع عشوائياً) } & \multicolumn{2}{|c|}{ النموذج الثاني (البديل الصحيح على البديلين جو د) } & \multicolumn{2}{|c|}{ النموذج الأول (البديل الصحيح على البديلين أو ب) } & \multirow[t]{2}{*}{ 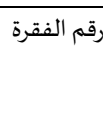 } \\
\hline الخطأ المعياري & معلمة الصعوبة & الخطأ المعياري & معلمة الصعوبة & الخطأ المعياري & معلمة الصعوبة & \\
\hline וTוT, & $\cdot, \mathrm{VA}-$ &., $19 r$ & $\cdot, \cdot r$ &., 199 & ., १९- & 1 \\
\hline., TYY & , ro &., 4 &., 90 &.,$Y Y Y$ &.,$\cdot r$ & $r$ \\
\hline., 197 & $\cdot, \mathrm{V} \varepsilon-$ &., $1 \leqslant 0$ & $\cdot, r$. &., roN & $1,19-$ & $r$ \\
\hline., $1 Y$. & $\cdot, 7 \mathrm{~V}-$ &.,$|Y|$ & $\cdot, .9-$ &., $\mathrm{Mrt}$ & $1, r \varepsilon$ & $\varepsilon$ \\
\hline., YOS & $1, Y \wedge-$ &., $1 V \varepsilon$ & $\cdot, \wedge \Lambda$ & $\cdot, Y .0$ &., $9 \varepsilon-$ & $\circ$ \\
\hline., $\mathrm{TVV}$ & $1, .7-$ &., $1 T$. & ., & . & $\cdot, \mathrm{VI}-$ & 7 \\
\hline$\cdot, \varepsilon \wedge \varepsilon$ & $1,0 \leqslant$ &., 0.0 & $1, \leqslant 0$ &., $7 \varepsilon 1$ & $1, r \mu$ & v \\
\hline., $1 \wedge \mathrm{V}$ &., $07-$ &., 171 & .,YK- &., 19 & $\cdot, \wedge .-$ & $\wedge$ \\
\hline., $19 \varepsilon$ &., ro &.,$Y r$. &., 49 &., 190 &., .0 & 9 \\
\hline , rOY & $\cdot, 97-$ &., $1 V$. & $\cdot, \mathrm{VI}$ &.,$r .1$ & $\cdot, \wedge \varepsilon-$ & 1. \\
\hline . &., 94 & . rTV & $1, \pi$ &.,$r \leqslant 0$ &., 71 & 11 \\
\hline.,$Y Y \Lambda$ &., ז人 & . $\{Y\}$ & 1, ro & $\cdot, r \ldots$ &.,$Y \varepsilon-$ & ir \\
\hline ., ros &., 94 &.,$r V \varepsilon$ & $1, \mathrm{rV}$ &., ґ१ &.,$\leqslant 1$ & 15 \\
\hline., $1 r 9$ &., ז人- &., 179 & ., VY - &., $1 V$. &., $9 .-$ & $1 \varepsilon$ \\
\hline.,$Y \wedge \varepsilon$ & $1,1 \mathrm{r}$ &., 10 & $1, r \varepsilon-$ &.,$r \leq \varepsilon$ & $1,11-$ & 10 \\
\hline . Trt & $\cdot, ., \varepsilon-$ &.,$r \leq 0$ & $\cdot, .9-$ & DT &., $10-$ & 17 \\
\hline .,Tr. & .,人ঙ- & . TH & $\cdot, .9-$ & D &., $07-$ & IV \\
\hline.,$r \leqslant 0$ & $\cdot, \wedge \mathrm{V}$ & $\cdot, \varepsilon 7 \varepsilon$ & 1,17 &., roV &.,$Y ו-$ & 11 \\
\hline.,$|V|$ &., 10 &., 119 &., $0 \leqslant$ &., ז . & $\cdot, \cdot \wedge-$ & 19 \\
\hline.,$r \cdot q$ & $\cdot, \leqslant 7$ &.,$Y T \varepsilon$ &.,$\mu$ & זY, &., 19 & r. \\
\hline , ror & $\cdot, \varepsilon \varepsilon$ &.,$I V V$ &., 49 & . TYE &., $00-$ & rI \\
\hline., 194 & $\cdot, 7 V-$ &., $1 \mathrm{~V}$ &.,$Y \backslash-$ & $\cdot, \varepsilon \cdot \wedge$ & $1, .1-$ & Mr \\
\hline.,$r \leqslant r$ &., 09 &., $09 \mathrm{r}$ & 1,9 &., 0.0 & . 94 & rT \\
\hline., $1 \mathrm{rV}$ & $\cdot, .0-$ &., $1 \leqslant$. &., 1 &., 190 & $\cdot, 7 Y-$ & $T \varepsilon$ \\
\hline ת זו, & $\cdot$, rI- &., 170 &., $0 .-$ & $\cdot, \mathrm{TV}$. & $1,11-$ & ro \\
\hline., 114 & $\cdot, \wedge Y$ &., 11. &., $0 \leqslant$ &.,$I V V$ &., $99-$ & $r 7$ \\
\hline ., rqr &.,$\Gamma \wedge$ &., $0 . r$ &., 99 & $\cdot, \Upsilon \wedge \Lambda$ & ., Yו- & TV \\
\hline 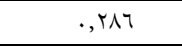 &., 77 &.,$\varepsilon r V$ & $1, r$ &.,$Y 17$ &., 19 & ru \\
\hline o & $\cdot, \cdot \varepsilon-$ &., $1 \leqslant 9$ &.,$r \cdot-$ & זחז,. &., $0 \mathrm{~V}-$ & $r q$ \\
\hline., $17 V$ &.,$V Y-$ &., 171 & $\cdot, r_{1}$ & . TAY & . ז人- & $r$. \\
\hline., $10 \mathrm{~V}$ &.,$Y V-$ & $\cdot, 1 \leqslant \wedge$ & ., $\Sigma 9-$ &.,$I T V$ &.,$Y \wedge-$ & ri \\
\hline
\end{tabular}

جدول (9): المتوسط الحسابي والانحراف المعياري لمعلمة الصعوبة والأخطاء المعيارية في دقة تقديرها لفقرات الاختبارللنماذج الثلاثة

\begin{tabular}{|c|c|c|c|c|}
\hline \multicolumn{2}{|c|}{ الانحراف المعياري } & \multicolumn{2}{|c|}{ المتوسط الحسابي } & \multirow[t]{2}{*}{ 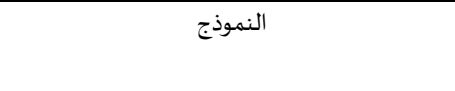 } \\
\hline الخطأ المعياري & معلمة الصعوبة & الخطأ المعياري & معلمة الصعوبة & \\
\hline., 1.9 &., $7 \varepsilon$ &., YVT &.,$\varepsilon \cdot-$ & النموذج الأول (البديل الصحيح على البديلين أو ب) \\
\hline., $1 \Gamma \varepsilon$ & $\cdot, \wedge 1$ & $\cdot, r 01$ & $\cdot, T \varepsilon$ & النموذج الثاني (البديل الصحيح على البديلين ج و د) \\
\hline., .10 & $\cdot, \mathrm{VT}$ & $\cdot, \pi$ ז &., $11-$ & النموذج الثالث (البديل الصحيح موزع عشوائيًا) \\
\hline
\end{tabular}

لا بد أن نوضح أولا أن صعوبة الفقرة تحدد مكان فعالية الفقرة على مقياس القدرة فعلى سبيل المثال الفقرة السهلة تظهر فعاليتها بين

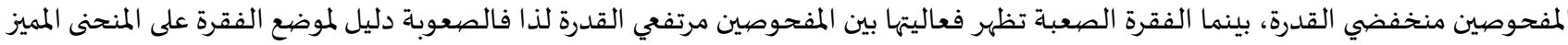

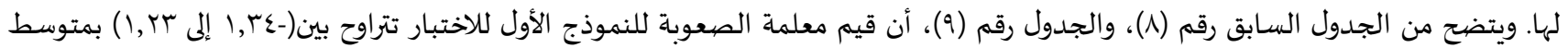

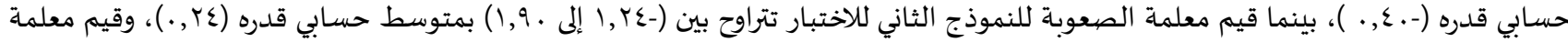

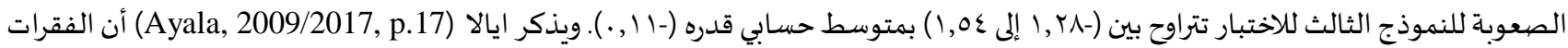
التي تتراوح قيمتها تحت الصفر و-Y توصف بأهها فقرات سهلة، والفقرات التي فوق الصفر فقرات صعبة. أما الفقرات التي قيمتها حوالي الصفر تعتبر 
متوسطة الصعوبة. وبناءً على ما تقدم نلاحظ بأن المتوسط الحساب لقيم معلمة الصعوبة للنماذج الثلاثة تقترب من الصفر وهذا يدل على أن فقرات

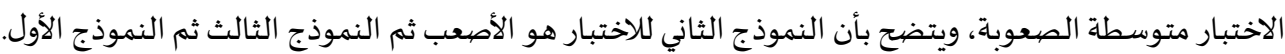
أما ما يتعلق بالخطأ المعياري لتقدير معلمة الصعوبة فهو دلالة على دقة تقدير معلمة الصعوبة وهو أدق من تقدير معلمة الصعوبة نفسها.

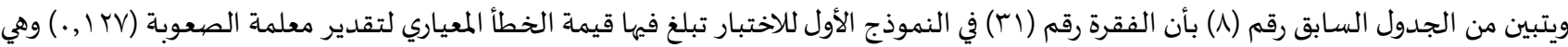
أقل قيمة في الجدول بالنسبة للنموذج الأول للاختبار، وبالتالي تُعد هذه الفقرة أكثر دقة في تقدير معلمة الصعوبة. والفقرة رقم (Y7) في النموذج الثاني

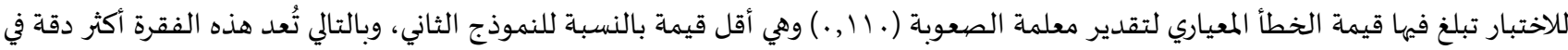

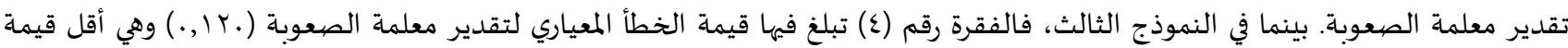

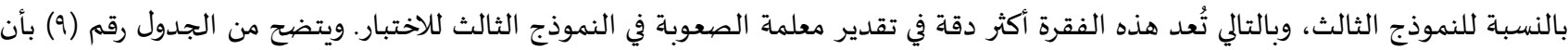
المتوسط الحسابي للأخطاء المعيارية في دقة تقدير معلمة الصعوبة للنموذج الثالث هو الأقل خطاءً مقارنة ببقية النماذج، ثم النموذج الثاني وأخيرًا النموذج الأول. وللكشف عن الدلالة الإحصائية للفروق بين المتوسطات الحسابية للأخطاء المعياربة في دقة تقدير معلمة الصعوبة للنماذج الثلاثة للاختبار

باختلاف موقع البديل الصحيح، تم استخدام تحليل التباين الأحادي، وتظهر النتائج في الجدول رقم (. ().

جدول ( ـ (): نتائج تحليل التباين الأحادي للكشف عن الفروق بين المتوسطات الحسابية للأخطاء المعيارية في دقة تقدير معلمة الصعوبة باختلاف موقع البديل الصحيح

\begin{tabular}{|c|c|c|c|c|c|}
\hline الدلالة الإحصائية & ق قيمة F & متوسط المربعات & الدرجات الحرية & مجموع المربعات & مصدر التباين \\
\hline \multirow[t]{3}{*}{ • } & ., 9 . &., $.1 Y$ & r & ., & 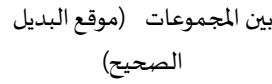 \\
\hline & &., .14 & 9. & $1,11 \varepsilon$ & داخل المجموعات (الخطأ) \\
\hline & & & 94 & $1,1+1$ & الكلي \\
\hline
\end{tabular}

ويتبين من الجدول رقم ( • 1) عدم وجود فروق دالة إحصائيًا عند مستوى الدلالة (ه. . .) بين المتوسطات الحسابية للأخطاء المعيارية في دقة

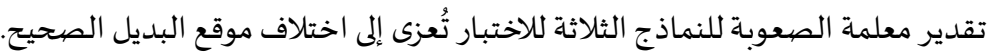

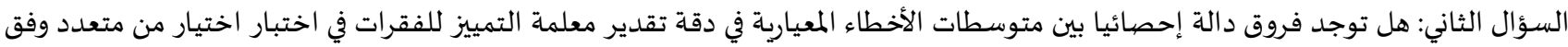

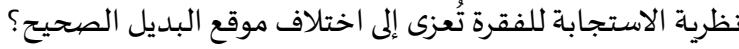
للإجابة عن هذا السؤال تم استخدام برنامج (Bilog-Mg3) لحساب الخطأ المعياري في دقة تقدير معلمة التمييز لفقرات الاختبار وذلك للنماذج الثلاثة للاختبار، كما هو موضيح في الجدول رقم (1) والذي يوضح كذلك تقديرات معلمة التمييز. وحساب المتوسط الحسابي والانحراف المعياري لدقة

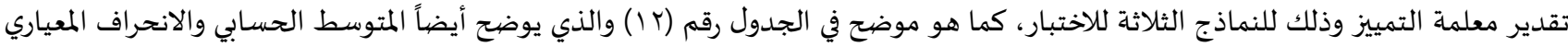
لتقديرات معلمة التمييز.

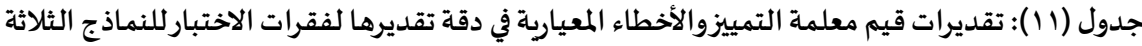

\begin{tabular}{|c|c|c|c|c|c|c|}
\hline \multicolumn{2}{|c|}{ النموذج الثالث (البديل الصحيح موزع عشوائيًا) } & \multicolumn{2}{|c|}{ النموذج الثاني (البديل الصحيح على البديلين ج و د) } & \multicolumn{2}{|c|}{ النموذج الأول (البديل الصحيح على البديلين أو ب) } & \multirow[t]{2}{*}{ 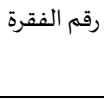 } \\
\hline الخطأ المعياري & 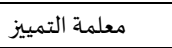 & الخطأ المعياري & 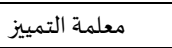 & الخطأ المعياري & 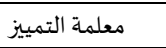 & \\
\hline.,$\Upsilon \varepsilon$ & $\cdot, 9$ &., 197 & $\cdot, \wedge$ & 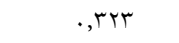 & $1, r r$ & 1 \\
\hline$\cdot, 19 \mathrm{~V}$ & $\cdot, \wedge 7$ & . , rir & $1, .0$ & ., |V| & $\cdot, \mathrm{Vr}$ & r \\
\hline$\cdot$, Yo\& & $1, .0$ & $\cdot$, TVY & $1, \varepsilon Y$ & $\cdot, 117$ & $\cdot, 79$ & $r$ \\
\hline$\cdot, 011$ & $1, \lambda 1$ & $\cdot, r \leq 7$ & $1,7 \varepsilon$ & . TTV & $\cdot, \wedge 7$ & $\varepsilon$ \\
\hline$\cdot$, & 1,or & 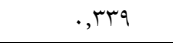 & $1, £ 0$ & $\cdot$, t八 & l, r. & $\circ$ \\
\hline$\cdot, r \cdot \cdot$ & $\cdot, 9 \mathrm{~V}$ & $\cdot, r \varepsilon \wedge$ & 1,70 & ., & l,v. & 7 \\
\hline$\cdot ., 1 \pi$ & .,or & $\cdot, 1 \mathrm{r}$ & $\cdot, \varepsilon \wedge$ & $\cdot, \cdot \wedge$ & $\cdot, r$. & v \\
\hline , roo & $\cdot, 99$ & $\cdot,+10$ & $1, . \varepsilon$ & $\cdot$, , 01 & 1,19 & $\wedge$ \\
\hline 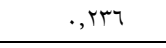 & $1, \cdot r$ &., 110 & •,AV & $\cdot, r \cdot V$ & $\cdot, \wedge \wedge$ & 9 \\
\hline.,$Y \neg \varepsilon$ &., $9 V$ & . & $1, r \varepsilon$ &.,$r .$. & $1,1 \varepsilon$ & 1. \\
\hline., 170 &., 79 &., $\mathrm{Vr}$ & •, AY &., $1 \leqslant r$ &., $0 \varepsilon$ & 11 \\
\hline.,$I V T$ & ., 19 & $\cdot, 1 \leqslant \wedge$ &., 09 &., $1 \leqslant V$ & , or & Ir \\
\hline., $1 \leqslant r$ &., 09 &., $10 \varepsilon$ & . 77 & ש & . $\{Y T$ & $1 \pi$ \\
\hline., 419 & $1, \varepsilon Y$ &.,$\Gamma \mid \varepsilon$ & $1, Y 7$ &.,$r \varepsilon$. & 1,or & $1 \varepsilon$ \\
\hline
\end{tabular}




\begin{tabular}{|c|c|c|c|c|c|c|}
\hline.,$Y M I$ & $\cdot, \wedge 9$ & $\cdot, r l$. & $\cdot, \wedge 7$ & צחז,. & 1,19 & 10 \\
\hline דr|, & $\cdot,\{\wedge$ &., 101 & .,77 &., 119 & $\cdot, V \varepsilon$ & 17 \\
\hline ., YTV &., 99 &., $1 V 7$ &., $\mathrm{Vr}$ &., 190 &.,$\vee 9$ & IV \\
\hline., $1 \leq \varepsilon$ &., 09 & זrו,. &.,$\leq 0$ & זrו, & $\cdot, \leq \varepsilon$ & 11 \\
\hline.,$r 99$ & 1,19 & $\cdot, r \varepsilon r$ & $1, r \mid$ &., 100 & . & 19 \\
\hline$\cdot, Y \cdot Y$ &., 97 &., $17 \varepsilon$ &., $\mathrm{Vr}$ &., 190 &., 19 & $r$. \\
\hline., $1 \vee \wedge$ & $\cdot, V \varepsilon$ & $\cdot, r \ldots$ & $1, .7$ &., $1 \leqslant 1$ &., 00 & $M$ \\
\hline., rol & $1, . r$ & $\cdot, r \cdot V$ & $1, \cdot r$ &., $1 \leqslant r$ &., $0 \varepsilon$ & rr \\
\hline., $1 \mathrm{rV}$ &., 01 & דו, &., 0 . &., 1.7 &.,$M 7$ & rr \\
\hline . & $1, £ \wedge$ & $\cdot, \Gamma \cdot \varepsilon$ & $1, \varepsilon \varepsilon$ & , ror &., $9 \vee$ & $r \varepsilon$ \\
\hline.,$r \leqslant V$ & $1, r v$ & ס ז ז, & $1,1 \pi$ & $\cdot$, TVT &., 90 & ro \\
\hline., orर & $1, v \wedge$ &.,$\leqslant 0$. & $1,9 V$ &.,$\leqslant \mid V$ & $1,0 \mathrm{~V}$ & rT \\
\hline., $1 \leqslant \lambda$ &., 09 &., $1 . r$ &.,$r V$ &., 10 &., $\mathrm{OV}$ & TV \\
\hline.,$I V r$ & $\cdot, \mathrm{V}$. & $\cdot, 1 \leqslant$. &., $0 \leqslant$ &., $1 \mathrm{VV}$ & $\cdot, \wedge$ & rA \\
\hline., Y7o & $1, r V$ & אTr, & $1, r \varepsilon$ & $\cdot, \backslash \wedge \mathrm{V}$ & $\cdot, \vee \vee 9$ & rq \\
\hline סזז,. & $1, \mathrm{rA}$ & $\cdot, r \backslash \Lambda$ & $1, .9$ &., $10 \leqslant$ &., 7 & $r$. \\
\hline ., ro7 & $1,1$. & $\cdot, Y \wedge \varepsilon$ & $1, r 9$ & , , & $1,0 Y$ & M \\
\hline
\end{tabular}

جدول (r ا ): المتوسط الحسابي والانحراف المعياري لمعلمة التمييزوالأخطاء المعيارية في دقة تقديرها لفقرات الاختبار للنماذج الثلاثة

\begin{tabular}{|c|c|c|c|c|}
\hline \multicolumn{2}{|c|}{ الانحراف المعياري } & \multicolumn{2}{|c|}{ المتوسط الحسابي } & \multirow[t]{2}{*}{ 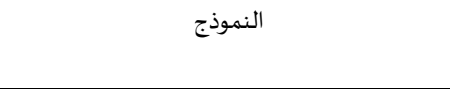 } \\
\hline الخطأ المعياري & معلمة التمييز & الخطأ المعياري & معلمة التمييز & \\
\hline., .94 & . ז^ &.,$Y 19$ & $\cdot, 17$ & النموذج الأول (البديل الصحيح على البديلين أو ب) \\
\hline .,.人r & . ६. & . TY & $1, .1$ & النموذج الثاني (البديل الصحيح على البديلين ج و د) \\
\hline$\cdot, 1 \cdot v$ & $\cdot, \mathrm{r}$ & ., ro\& & $1, .$. & النموذج الثالث (البديل الصحيح موزع عشوائيًا) \\
\hline
\end{tabular}

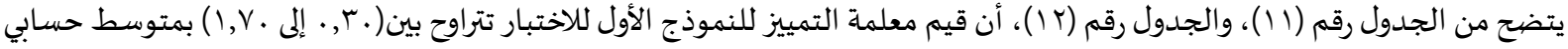

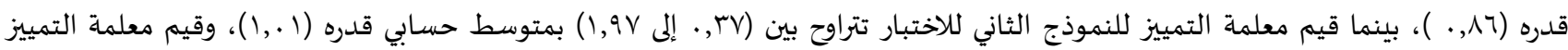

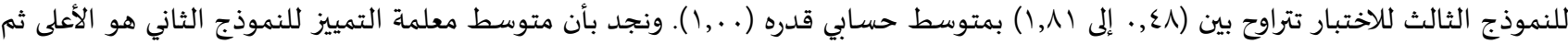

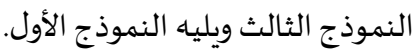
ويتضح من الجدول السابق رقم (11) بأن الفقرة رقم (V) في النموذج الأول للاختبار تبلغ فهها قيمة الخطأ المعياري لتقدير معلمة التمييز

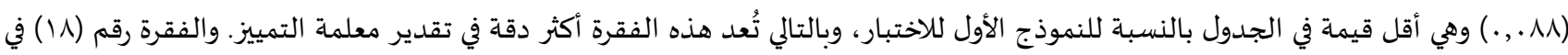

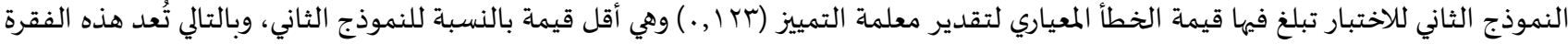

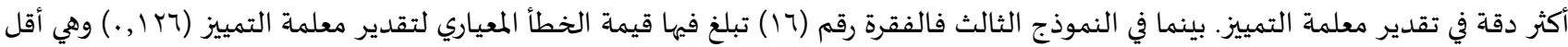

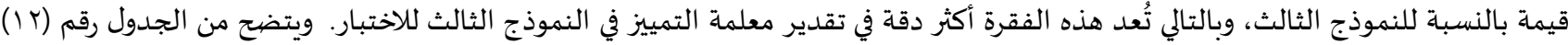
بأن المتوسط الحسابي للأخطاء المعيارية في دقة تقدير معلمة التمييز للنموذج الأول هو الأقل خطاءً مقارنة ببقية النماذج، ثم النموذج الثانية الناني وأخيرًا

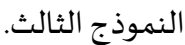
وللكشف عن الدلالة الإحصائية للفروق بين المتوسطات الحسابية للأخطاء المعيارية في دقة تقدير معلمة التمييز للنماذج الثلاثة للاختبار

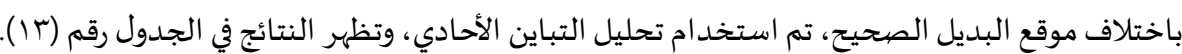

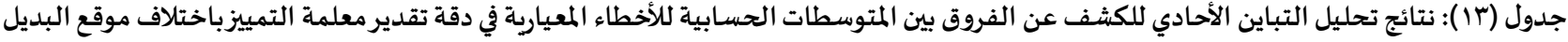

\begin{tabular}{|c|c|c|c|c|c|}
\hline \multicolumn{6}{|c|}{ الصحيح } \\
\hline الدلالة الإحصائية & قيمة F F F F & متوسط المربعات & الدرجات الحربة & مجموع المربعات & مصدر التباين \\
\hline 促 & $1, r \wedge 0$ &., .11 & r &.,$\pi T$ & $\begin{array}{c}\text { بين المجموعات (موقع البديل } \\
\text { بلصحيح) }\end{array}$ \\
\hline & &.,. .9 & १. & ., 199 & داخل المجموعات (الخطا) \\
\hline
\end{tabular}

ويتبين من الجدول رقم (rا ) عدم وجود فروق دالة إحصائيًا عند مستوى الدلالة (ه. . .) بين المتوسطات الحسابية للأخطاء المعيارية في دقة تقدير معلمة التمييز للنماذج الثلاثة للاختبار تُعزى إلى اختلاف موقع البدوفيل الصنحيح.

$\Lambda$. 
السؤال الثالث: هل توجد فروق ذات دلالة إحصائية بين متوسطات تقديرات معاملات الثبات التجريبي في اختبار اختيار من متعدد وفق نظرية

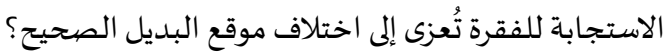
لإجابة عن هذا السؤال تم استخدام برنامج (Bilog-Mg3) لحساب معاملات الثبات التجريبي لكل نموذج من النماذج الثلاثة للاختبار، والجدول رقم

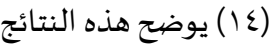

جدول (ع ( ): نتائج قيم معاملات الثبات التجريبي لنماذج الاختبار الثلاثة

\begin{tabular}{|c|c|}
\hline معامل الثبات التجريبي & النموذج \\
\hline$\cdot, 10$ & النموذج الأول (موقع البديل الصحيح على البديلين أو ب) \\
\hline$\cdot, \mathrm{s}$ & النموذج الثاني (موقع البديل الصحيح على البديلين ج و د) \\
\hline$\cdot, \mathrm{AV}$ & النموذج الثالث (موقع البديل الصحيح موزع عشوائيًا) \\
\hline
\end{tabular}

يتضح من الجدول رقم (ع ا ) أن قيمة معامل الثبات التجريبي للنموذج الثاني (موقع البديل الصحيح على البديلين ج و د) هي الأعلى قيمة، وبالتالي هي الأكثر ثباتًا من النماذج الأخرى للاختبار ويلها النموذج الثالث (موقع البديل الصحيح موزع عشوائيًا)، واخيرًا النموذج الأول (موقع البديل الصحيح على البديلين أو ب).

ولمعرفة دلالة الفروق في معاملات الثبات التجريبي بين نماذج الاختبار الثلاثة، فقد تم استخدام الاختبار الإحصائي (M) والذي يتبع توزيع

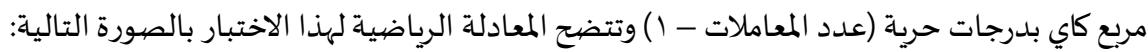

$$
\mathrm{M}=\frac{\mathrm{J}-1}{18 \mathrm{~J}}\left\{\sum_{\mathrm{K}=1}^{\mathrm{K}} \mathrm{B}_{\mathrm{K}}-\frac{\left[\sum_{\mathrm{K}=1}^{\mathrm{K}} \mathrm{B}_{\mathrm{K}}\left(1-\mathrm{r}_{\mathrm{k}}\right)^{\frac{-1}{3}}\right]^{2}}{\sum_{\mathrm{K}}^{\mathrm{K}} \mathrm{B}_{\mathrm{K}}\left(1-\mathrm{r}_{\mathrm{k}}\right)^{\frac{-2}{3}}}\right\}
$$

$$
B_{K}=\frac{\left(9 n_{k}-11\right)^{2}}{n_{k}-1}
$$

حيث تُحسب B من المعادلة التالية: حيث إن ...

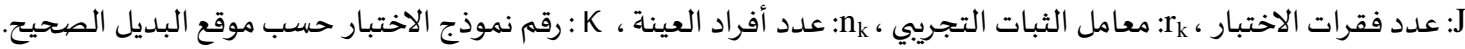
وتم حساب قيمة الإحصائي (M) لكل مقارنة بين نماذج الاختبار الثلاثة لحساب معامل الثبات التجريبي كما تظهر في الجدول رقم (10).

جدول(10): قيم الإحصائي (M) للمقارنات الثنائية بين معاملات الثبات التجريبي لنماذج الاختبار الثلاثة

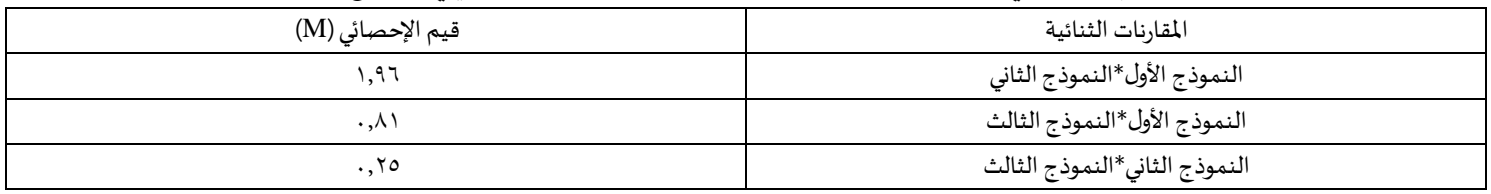

من الجدول رقم (10) يتضح أن جميع قيمة (M) المحسوبة أقل من القيمة الحرجة لتوزيع كاي تربيع بدرجة حرية (1) وعند مستوى دلالة (0. . .) والتي تساوي (ع,^r)، والذي يدل على عدم وجود فروق ذات دلالة إحصائية بين قيم معاملات الثبات التجريبي لنماذج الاختبار الثلاثة، وهذا

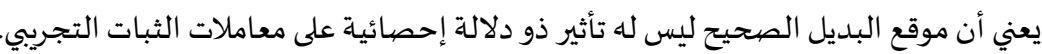

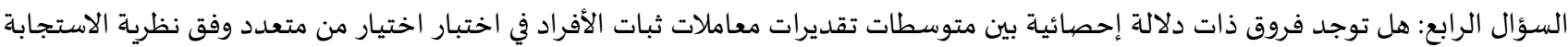

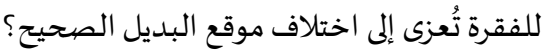
للإجابة عن هذا السؤال تم حساب معامل الفصل بين الأفراد للنماذج الثلاثة للاختبار من خلال المعادلة التالية:

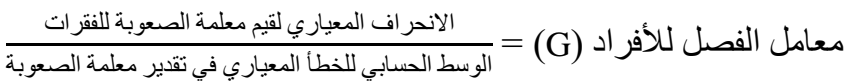

ويتم استخراج هذه القيم من خلال نتائج برنامج (Bilog-Mg3).

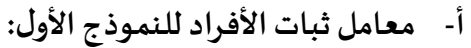
في النموذج الأول للاختبار تبلغ قيمة الانحراف المعياري لقيم معلمة الصعودة الهولة للفقرات (عاب,.) وقيمة الوسط الحسابي للخطأ المعياري في تقدير

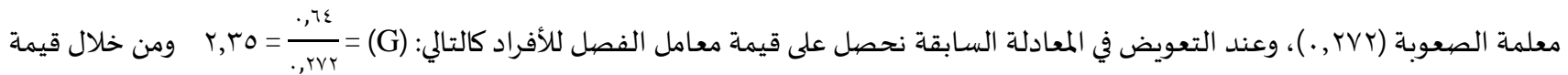
معامل الفصل للأفراد يتم حساب معامل ثبات الأفراد من المعادلة التالية: 
معامل ثبات الأفراد = $\frac{G^{2}}{1+G^{2}}$

معامل ثبات الأفراد للنموذج الأول:

ب- معامل ثبات الأفراد للنموذج الثاني: ما يتعلق بالنموذج الثاني للاختبار فتبلغ قيمة الانحراف المعياري لقيم معلمة الصعوبة للفقرات (1/, •) وقيمة الوسط الحسابي للخطأ المعياري في تقدير معلمة الصعوبة (اهץ, .) وعند التعويض في معادلة معامل الفصل للأفراد نحصل على القيمة التالي: (G) = معامل الفصل للأفراد يتم حساب معامل ثبات الأفراد من المعادلة التالية: معامل ثبات الأفراد للنموذج الثاني = ج- معامل ثبات الأفراد للنموذج الثالث: في النموذج الثالث للاختبار تبلغ قيمة الانحراف المعياري لقيم معلمة الصعوبة للفقرات (VT, . ) وقيمة الوسط الحسابي للخطأ المعياري في تقدير معلمة الصعوبة (ع سr, . ) وعند التعويض في معادلة معامل الفصل للأفراد نحصل على التالي: (G) = عrr للأفراد يتم حساب معامل ثبات الأفراد من المعادلة التالية: معامل ثبات الأفراد للنموذج الثالث = ومن خلال الجدول رقم (7 1 ) يتضح قيم معاملات ثبات الأفراد للنماذج الثلاثة للاختبار. جدول (17) (17) نتائج قيم معاملات ثبات الأفراد لنماذج الاختبار الثلاثة

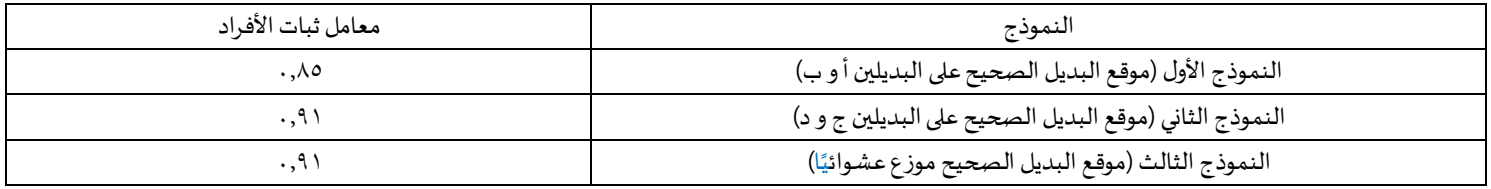

يتضح من الجدول رقم (17) بأن النموذج الثاني (موقع البديل الصحيح على البديلين ج و د) والنموذج الثالث (موقع البديل الصحيح موزع

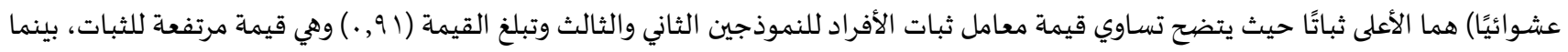

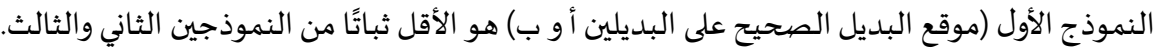

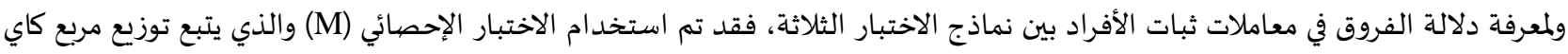

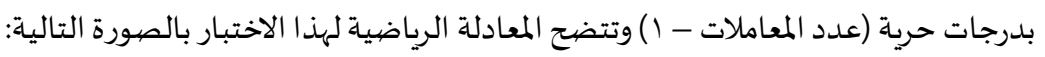

$$
\begin{gathered}
M=\frac{J-1}{18 J}\left\{\sum_{\mathrm{K}=1}^{\mathrm{K}} \mathrm{B}_{\mathrm{K}}-\frac{\left[\sum_{\mathrm{K}=1}^{\mathrm{K}} \mathrm{B}_{\mathrm{K}}\left(1-\mathrm{r}_{\mathrm{k}}\right)^{\frac{-1}{3}}\right]^{2}}{\sum_{\mathrm{K}}^{\mathrm{K}} \mathrm{B}_{\mathrm{K}}\left(1-\mathrm{r}_{\mathrm{k}}\right)^{\frac{-2}{3}}}\right\} \\
\mathrm{B}_{\mathrm{K}}=\frac{\left(9 \mathrm{n}_{\mathrm{k}}-11\right)^{2}}{\mathrm{n}_{\mathrm{k}}-1}
\end{gathered}
$$

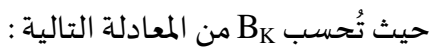

$$
\text { حيث إن . إن إد }
$$

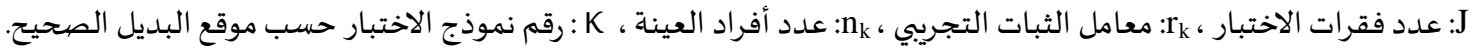

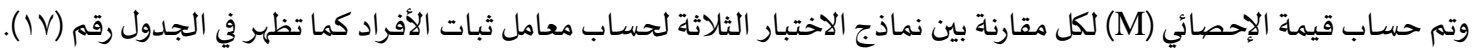
جدول (IV) : قيم الإحصائي (M) للمقارنات الثنائية بين معاملات ثبات الأفراد لنماذج الاختبار الثلاثة

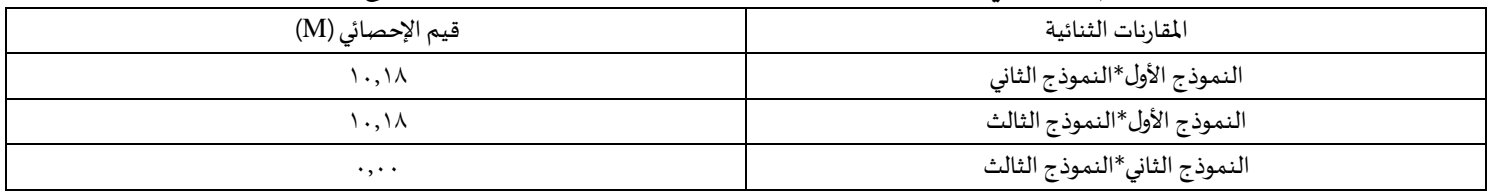


من الجدول رقم (VI) يتضح أن بعض قيم (M) المحسوبة أعلى من القيمة الحرجة لتوزيع كاي تربيع بدرجة حرية (1) وعند مستوى دلالة

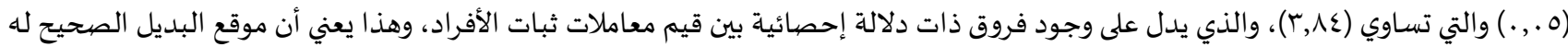
تأثير ذو دلالة إحصائية على معاملات ثبات الأفراد. حيث يوجد فروق ذات دلالة إحصائية بين النموذج الأول (موقع البديل الصحيح على البديلين أو وأو

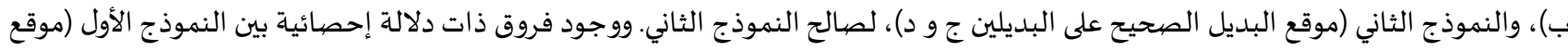

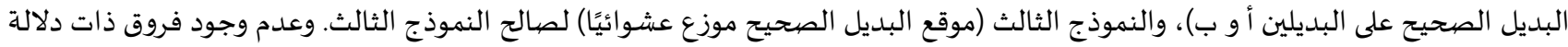

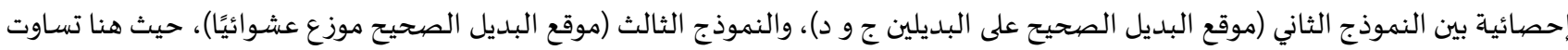

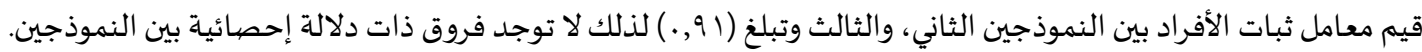

مناقشـة نتائج البحث:

أظهرت النتائج المتعلقة بتحقق افتراضات نظرية الاستجابة للفقرة للنموذج ثنائي المعلمة وبالتحديد افتراض أحادية البعد بأن قيمة الجذر الكامن للعامل الأول إلى قيمة الجذر الكامن للعامل الثاني كانت أعلى من (r) للنماذج الثلاثة للاختبار، وهذا يدل على وجود سمة سـائدة للاختبار ، وهذه

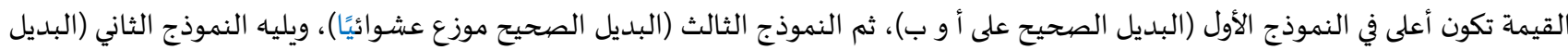

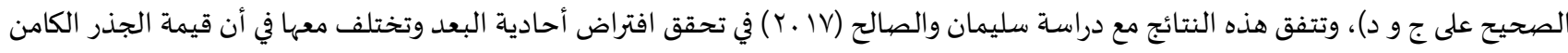

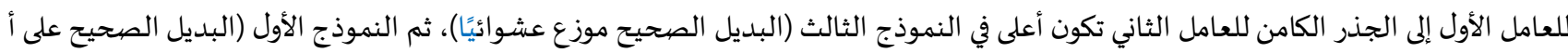
و ب)، ويليه النموذج الثاني (البديل الصحيح على ج و د).

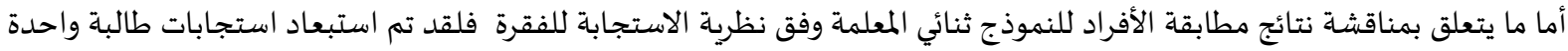

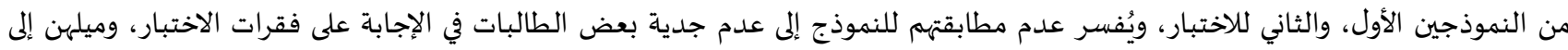

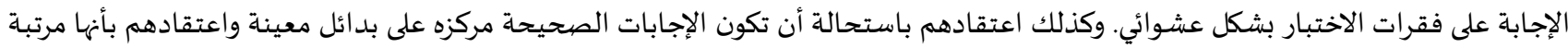

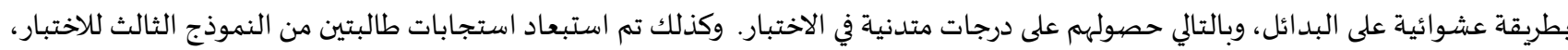
وذلك بسبب حصولهم على درجات مرتفعة. وتتفق هذه النتائج مع دراسة سليمان والصالح (Y V V) في أن النموذج الثاني للاختبار تم فياه استبعاد

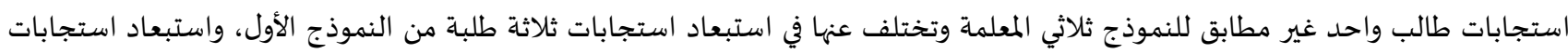
طالب واحد من النموذج الثالث.

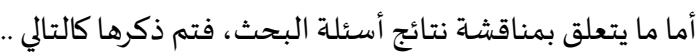

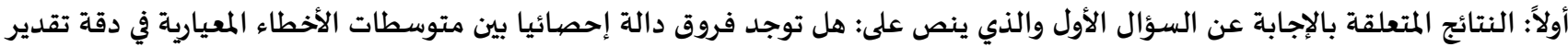

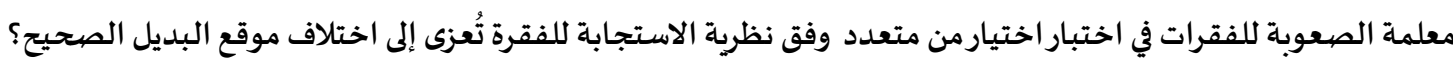

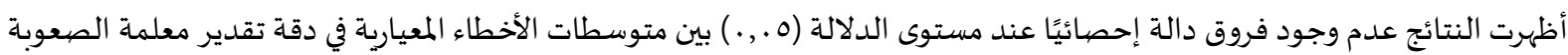

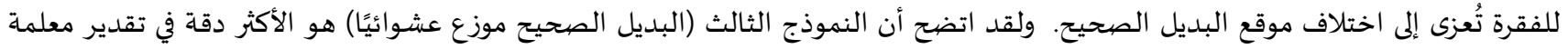

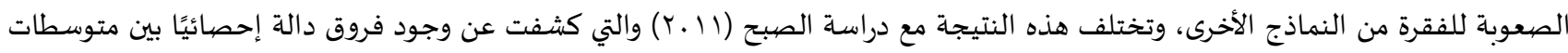

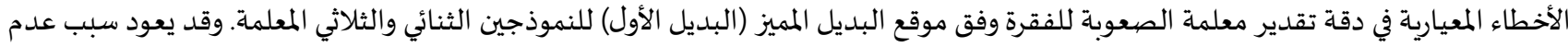

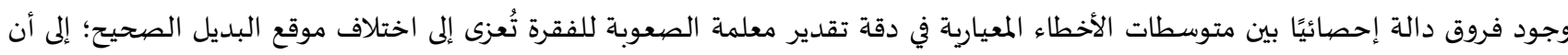
محتوى الاختبار واحد لكل النماذج الثلاثة، وربما يكون السبب الأخر هو أن الطالبات لا يمتلكن مهارة حكمة الاختبات دهبار.

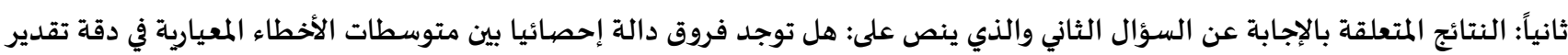
معلمة التمييز للفقرات في اختبار اختيارمن متعدد وفق نظرية الاستجابة للفقرة تُعزى إلى اختلاف موقع البديل الصنحيح؟

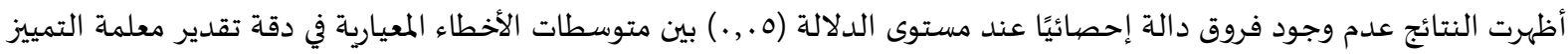

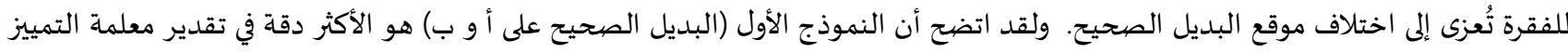

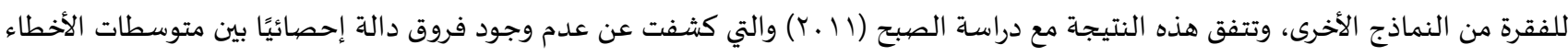

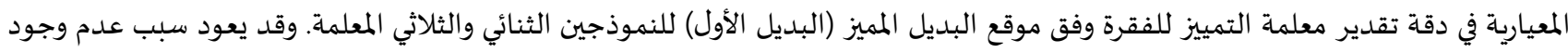

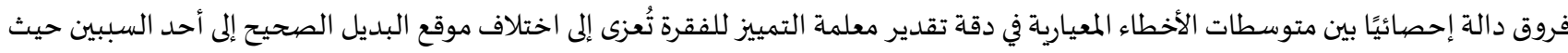
السبب الأول قد يتمحور حول أن محتوى الاختبار واحد لكل النماذج الثلاثة للاختبار، والسبب الثاني ربما يعود إلى عدم امتلاك الطالبات لمتات لمهارة حكمة

الاختبار. 
ثالثاً: النتائج المتعلقة بالإجابة عن السؤال الثالث والذي ينص على: هل توجد فروق ذات دلالة إحصائية بين متوسطات تقديرات معاملات

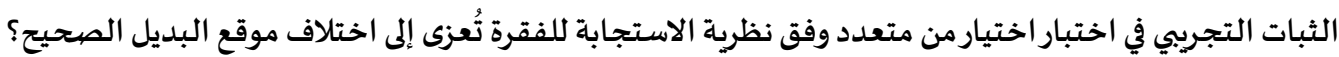

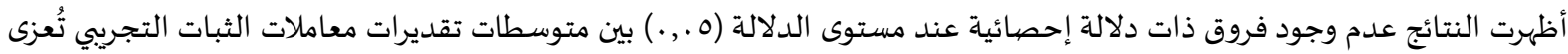
إلى اختلاف موقع البديل الصحيح. واختلفت هذه النتيجة مع دراسة سليمان والصالح (Y. VV)، والتي توصلت إلى وجود فروق ذات ذات دلالة إحصائية بين متوسطات تقديرات معاملات الثبات التجريبي تُعزى إلى اختلاف موقع البديل الصحيح.

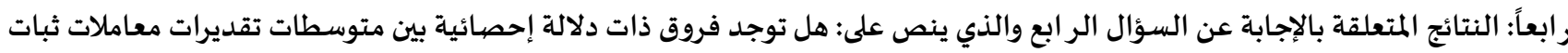

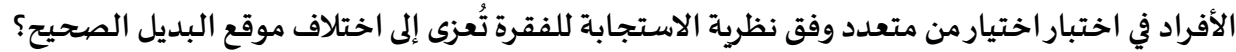

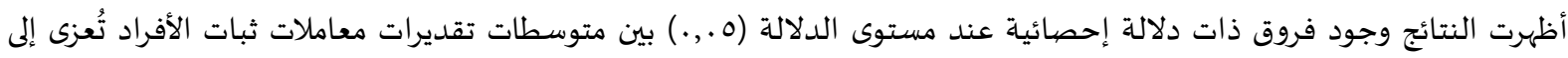

اختلاف موقع البديل الصحيح، وذلك لصالح النموذجين الثاني (البديل الصحيح على ج و د)، والثالث (البديل الصحيح موزع عشوائيًَا). التوصيات:

بناءً على ما تم التوصل إلياء من نتائج، يمكن الخروج بالتوصيات التالية:

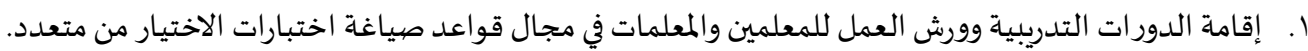
r. توعية المعلمين والمعلمات إلى ضرورة العناية بفقرات اختبار الاختيار من متعدد عند إعدادها وكذلك ضرورة العناية بتوزيع الإجابات

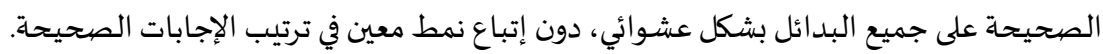
r. إجراء المزيد من البحوث والدراسات حول أثر موقع البديل الصحيح في اختبار اختيار من متعدد في مواد دراسية مختلفة، وفي مراحل دراسية

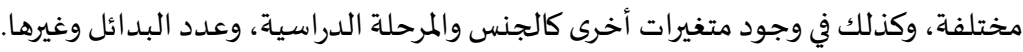
المقترحات:

1. الكشف عن أثر موقع البديل الصحيح في اختبار اختيار من متعدد على تحصيل الطلبة.

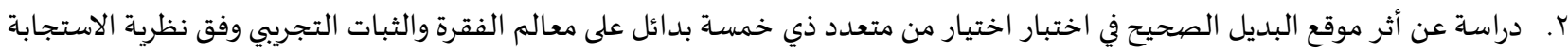
للفقرة. r. دراسة مقارنة بين نموذج اختبار اختيار من متعدد ذي أربعة بدائل ونموذج اختبار اختيار من متعدد ذي ثلاثة بدائل في ضوء موقع البديل الصحيح وفق نظرية الاستجابة للفقرة. ع. دراسـة مقارنة بين النظرية التقليدية في القياس، ونظرية الاستجابة للفقرة في ضوء موقع البديل الصحيح وأثره على معلمة الصعوبة والتمييز.

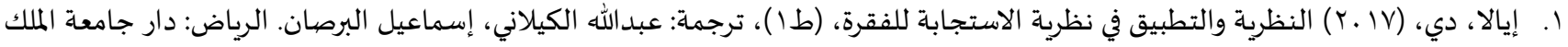
سعود للنشر.

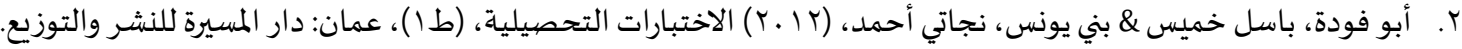

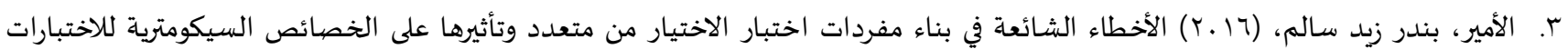

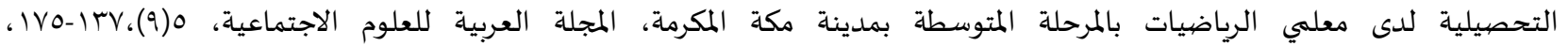
https://doi.org/10.12816/0033017 ع. أيكين، لويس ر، (V . . r) الاختبارات والامتحانات قياس القدرات والأداء، (ط ا)، ترجمة: فرح السراج. الرياض : شركة العبيكان للأبحاث والتطوير.

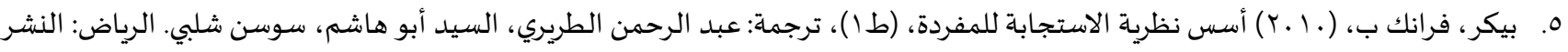

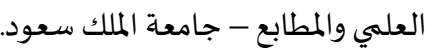

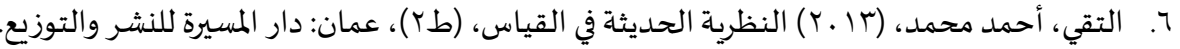
V

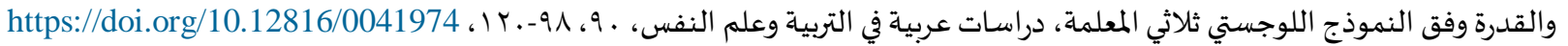

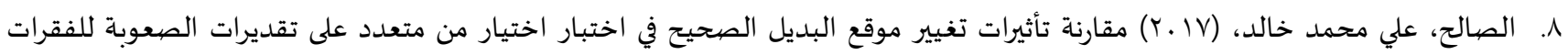

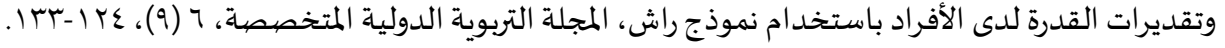




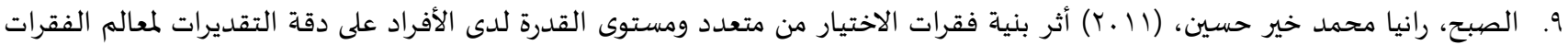

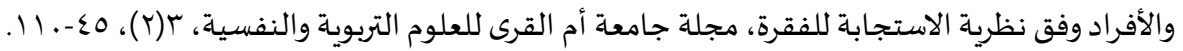

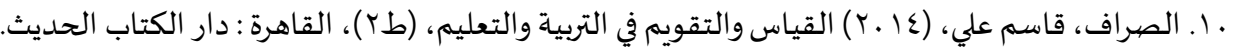

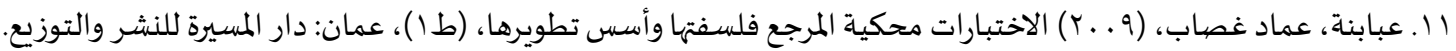

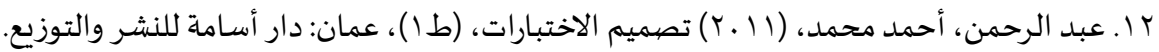

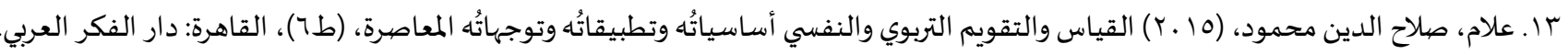

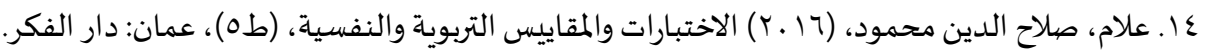

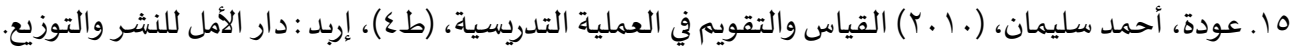

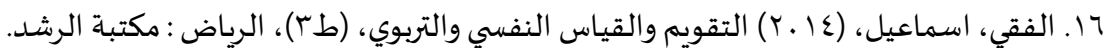

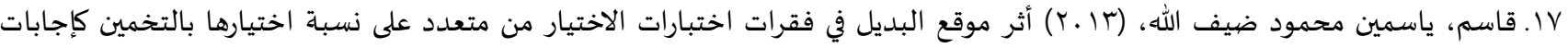
صحيحة للفقرة، رسالة ماجستير غير منشورة، جامعة مؤتة، كلية العلوم التربوية، الأردن.

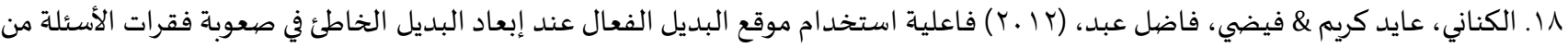

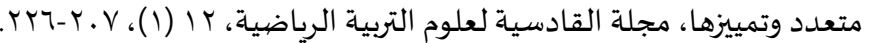

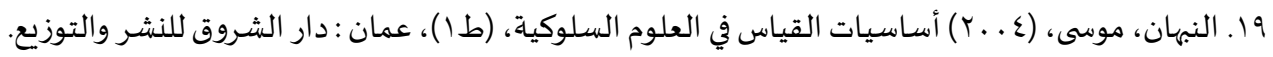

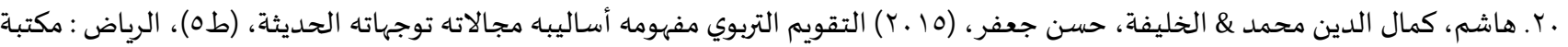
الرشد ناشرون.

\section{ثانياً: المراجع الأجنبية:}

[1] Baker. F., The Basic of item Response Theory, (2th Ed), USA: Eric Clearing House on Assessment and Evaluation, (2001)

[2] Cizek. G. J., The Effect of Altering the Position of Options in a Multiple-Choice Examination, Educational and Psychological Measurement, 54(1)(1994),8-20, https://doi.org/10.1177/0013164494054001002

[3] Hambleton. R., \& Swaminathan. H., Item Response Theory: Principles and applications, Boston: Kluwer Nijhoff Publishing, (1985)

[4] Hatti. J., An empirical study of various indices for determining unidimensionality, Multivariate Behavioral Research, 19(1)(1984), 49-78, https://doi.org/10.1207/s15327906mbr1901_3

[5] Kolawole. E. B. \& Olarotimi. J. T., A survey of the Anchor Bias in Mathematics Objective Tests in West African Examination Council (WAEC), Journal of Emerging Trends in Educational Research and Policy Studies (JETERAPS), 2(3)(2008),171-173.

[6] Lane. D. S. \& Bull. K. S., The effects of Knowledge of item arrangement Gender And Statistical and cognitive item Difficulty on Test Performance, Educational and Psychological Measurement, 47(4)(1987), 865- 879, https://doi.org/10.1177/0013164487474002

[7] Nwadinigwe. P., I. \& Naibi. L., The Number of Options in a Multiple-Choice Test Item and the Psychometric Characteristics, Journal of Education and Practice, Nigeria, 4(28)(2013), 189-196.

[8] Plake. B. Thompson. A. \& Lowry. S., Effects of item arrangement and test anxiety on two scoring methods, The Journal of Experimental Education, 49(4)(1984) 214- 219, https://doi.org/10.1080/00220973.1981.11011786

[9] Wevric. L, Response set in a multiple-choice test, Educational and psychological Measurement, (2001) (33). 


\title{
The Impact of the Correct Alternative Position in Multiple Choice Test on the Precision of Item Parameters Estimation According to Two Parameter Model of the Item Response Theory
}

\author{
Ashwaq Daifallah Selim Al-Marwani \\ M.Sc. in Measurement and Evaluation- University of Tabuk- KSA \\ A.ashwaqalmarwani@hotmail.com \\ Shaher Khalid Suleiman \\ Associate Professor of Measurement and Evaluation- University of Tabuk- KSA \\ s.suliman@ut.edu.sa
}

\begin{abstract}
This study aimed to detect the impact of the correct alternative position in multiple choice test with four alternatives on the precision of estimation difficulty parameter and item discrimination, and on the estimation of experiential reliability coefficients and individual reliability coefficients according to two parameter model of the item response theory.

To achieve research objectives, a multiple choice test with four alternatives in science was built consisted of (31) items and of three patterns with the same content and variable which is the correct alternative position where the first pattern is the correct alternative position on the two alternatives (A \& B) and the second pattern on the alternatives $(\mathrm{C} \& \mathrm{D})$ and the third pattern randomly distributes the correct alternative position on the four alternatives.

The three patterns were applied to a random clustered sample consisting of (500) third intermediate female students in Yanbu city. (SPSS) statistical program package and ( Bilog-Mg 3) were used for data analysis .

The results of the study indicated that there are no statistically significant differences between the means of precision of estimation difficulty parameter and item discrimination attributed to correct alternative position, and there are no statistically significant differences between the means of experiential reliability coefficients ratings attributed to correct alternative position attributed to correct alternative position, while there are no statistically significant differences between the means of individual reliability coefficients ratings attributed to correct alternative position.

In light of these results a number of recommendations were presented, the most notably are the male and female teacher's awareness of the need to take care of the multiple choice test items preparation, as well as the need to care in the distribution of the correct answers randomly to all alternatives .
\end{abstract}

Keywords: Correct Alternative Position, Multiple Choice Test, Precision of Item Parameters Estimation, Two Parameter Model, Item Response Theory.

\section{References:}

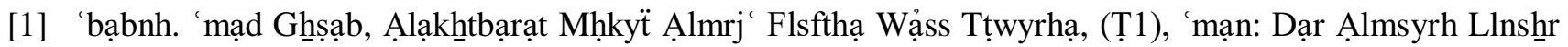
Wạltwzy', (2009)

[2] bd Ạlrḥmn. Ạhmọm Mḥmd, Tṣmym Ạlạkḥtbạrạt, (Ṭ1), 'mạn: Dạr osạma Llnsḥr Wạltwzy', (2011) 
[3] 'lạm. Șlạh Ạldyn Mḥmwd, Ạlqyạs Wạltqwym Ạltrbwy Wạlnfsy Ạ̉sạsyạatuh Wtṭbyqạtuh Wtwjhạtuh Ạlm’ạșrh, (Ṭ6), Ạlqạhrh: Dạr Ạlfkr Ạl'rby, (2015)

[4] 'lạm. Șlạh Ạldyn Mḥmwd, Ạlạkḥtbạrạt Wạlmqạyys Ạltrbwyh Wạlnfsyh, (Ṭ5), 'mạn: Dạr Ạlfkr, (2016)

[5] 'wdh. Ạ̉ḥmd Slymạn, Ạlqyạs Wạltqwym Fy Ạl'mlyh Ạltdrysyh, (Ṭ4), Ạrbd: Dạr Ạlạ̉ml Llnsḥr Wạltwzy', (2010)

[6] Ạ̉bw Fwdh. Bạsl Khnmys \& Bny Ywns. Njạty Ạhḥmd, Ạlạkḥtbạrạt Ạltḥ̣ṣlyh, (Ṭ1), 'mạn: Dạr Ạlmsyrh Llnshrr Wạltwzy', (2012)

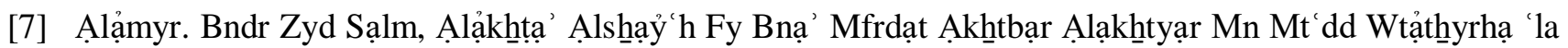

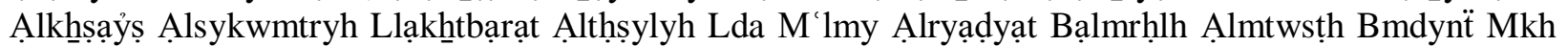
Ạlmkrmh, Ạlmjlh Ạl'rbyh Ll'lwm Ạlạjtmạ yh, 5(9)(2016),137-175, https://doi.org/10.12816/0033017

[8] Ạlfqy. Ạsmạ yl, Ạltqwym Wạlqyạs Ạlnfsy Wạltrbwy, (Ṭ), Ạlryạḍ : Mktbë Ạlrshhd, (2014)

[9] Ạlknạny. 'ạyd Krym \& Fyḍdy. Fạ̣ll 'bd, Fạ 'lyë Ạstkhdạm Mwq' Ạlbdyl Ạlf'ạl 'nd ẠB'ạd Ạlbdyl Ạlkhạtỷ Fy Ș'wbë Fqrạt Ạlạ̉sỷlh Mn Mt'dd Wtmyyzhạ, Mjlẗ Ạlqạdsyh L'lwm Ạltrbyh Ạ̉lryạḍh, 12(1)(2012), 207-226.

[10] Ạlnbhạn. Mwsa, Ạ̉sạsyạt Ạlqyạs Fy Ạl'lwm Ạlslwkyh, (Ṭ1), 'mạn: Dạr Ạlsḥrwq Llnsḥr Wạltwzy', (2004)

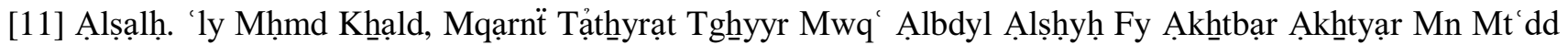

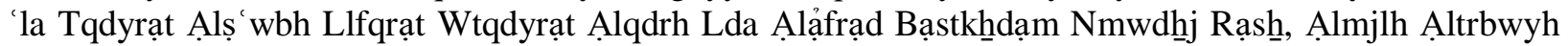
A.ldwlyh Ạlmtkḥșșh, 6(9) (2017), 124-133.

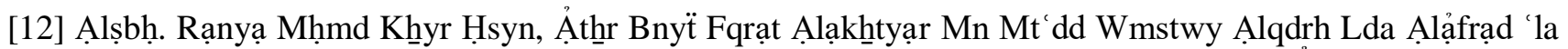

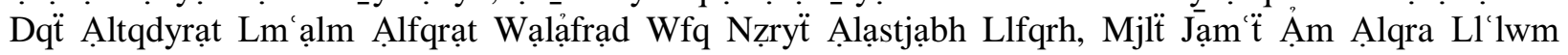
Ạltrbwyh Wạlnfsyh, 3(2)(2011), 45-110.

[13] Ạlșrạf. Qạsm 'ly, Ạlqyạs Wạltqwym Fy Ạltrbyh Wạlt lym, (Ṭ2), Ạlqạahrh: Dạr Ạlktạb Ạlḥdytḥ, (2014)

[14] Ạltqy. Ạ̉ḥmd Mḥmd, Ạlnẓryh Ạlḥdythַh Fy Ạlqyạs, (Ṭ), 'mạn: Dạr Ạlmsyrh Llnsḥr Wạltwzy', (2013)

[15] Ạyạlạ. Dy, Ạlnẓryh Wạltṭbyq Fy Nẓrÿ̈ Ạlạstjạbh Llfqrh, (Ṭ1), Trjmï: 'bdạllh Ạlkylạny, Ạsmạ yl

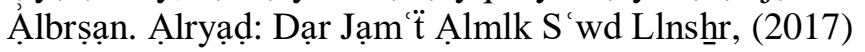

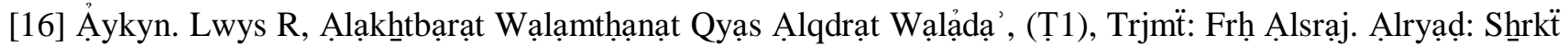
Ạl bykạn Llạ̉bhạath Wạltțwyr, (2007)

[17] Baker. F., The Basic of item Response Theory, (2th Ed), USA: Eric Clearing House on Assessment and Evaluation, (2001)

[18] Bykr. Frạnk B, Ạ̉ss Nẓryë Ạlạstjạbh Llmfrdh, (Ṭ1), Trjmï: 'bd Ạlrḥmn Ạlț̣yry, Ạlsyd Ạ̉bw Hạsḥm, Swsn

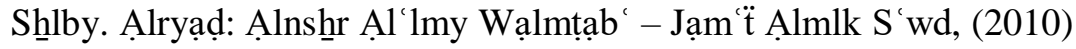

[19] Cizek. G. J., The Effect of Altering the Position of Options in a Multiple-Choice Examination, Educational and Psychological Measurement, 54(1)(1994),8-20, https://doi.org/10.1177/0013164494054001002

[20] Hambleton. R., \& Swaminathan. H., Item Response Theory: Principles and applications, Boston: Kluwer Nijhoff Publishing, (1985)

[21] Hạshِm. Kmạl Ạldyn Mḥmd \& Ạlkhlyfh. Ḥsn J'fr, Ạltqwym Ạltrbwy Mfhwmh Ạ̉sạlybh Mjạlạth Twjhạth Ạlḥ̣dythhh, (Ṭ5), Ạlryạ̣: Mktbë Ạlrsh̆d Nạshrrwn, (2015) 
[22] Hatti. J., An empirical study of various indices for determining unidimensionality, Multivariate Behavioral Research, 19(1)(1984), 49-78, https://doi.org/10.1207/s15327906mbr1901_3

[23] Kolawole. E. B. \& Olarotimi. J. T., A survey of the Anchor Bias in Mathematics Objective Tests in West African Examination Council (WAEC), Journal of Emerging Trends in Educational Research and Policy Studies (JETERAPS), 2(3)(2008),171-173.

[24] Lane. D. S. \& Bull. K. S., The effects of Knowledge of item arrangement Gender And Statistical and cognitive item Difficulty on Test Performance, Educational and Psychological Measurement, 47(4)(1987), 865-879, https://doi.org/10.1177/0013164487474002

[25] Nwadinigwe. P., I. \& Naibi. L., The Number of Options in a Multiple-Choice Test Item and the Psychometric Characteristics, Journal of Education and Practice, Nigeria, 4(28)(2013), 189-196.

[26] Plake. B. Thompson. A. \& Lowry. S., Effects of item arrangement and test anxiety on two scoring methods, The Journal of Experimental Education, 49(4)(1984) 214- 219, https://doi.org/10.1080/00220973.1981.11011786

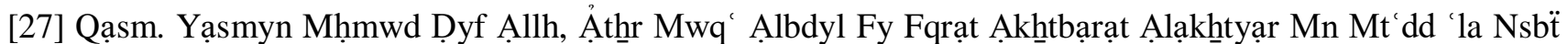

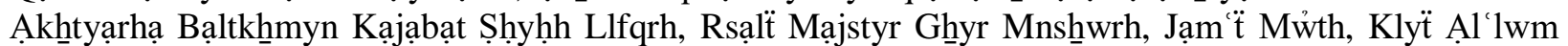
Ạltrbwyh, Ạlạ̉rdn, (2013)

[28] Slymạn. Shạhr Khạld \& Ạlṣalh. 'ly Mḥmd Khạald, Ạ̉ḥr Mwq Ạlbdyl Ạlṣ̣̣yḥ̣ Fy Ạkhtbạr Ạkhtyạr Mn Mt'dd 'la Tqdyrạt M'ạlm Ạlfqrạt Wạlqdrh Wfq Ạlnmwdh̆j Ạllwjsty Thlạthِy Ạlm 'lmh, Drạsạt 'rbyh Fy A.ltrbyh W'lm A.lnfs, 90(2017), 98-120, https://doi.org/10.12816/0041974

[29] Wevric. L, Response set in a multiple-choice test, Educational and psychological Measurement, (2001) (33). 